
NISTIR 7333

\title{
Feasibility of Using a Concrete Mixing Truck as a Rheometer
}

\author{
Sofiane Amziane \\ LG2M, Université de Bretagne Sud, France \\ Chiara F. Ferraris \\ Building and Fire Research Laboratory, NIST \\ Eric Koehler \\ University of Texas, Austin
}

September 2006

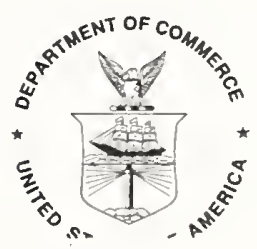

U.S. Department of Commerce Carlos M. Gutierrez, Secretary

Technology Administration

Robert Cresanti. Under Secretary of Commerce for Technology 


\section{Disclaimer}

Commercial equipment, instruments, and materials mentioned in this paper are identified to foster understanding. Such identification does not imply recommendation or endorsement by the National Institute of Standards and Technology (NIST), nor does it imply that the materials or equipment identified are necessarily the best available for the purpose. 


\section{ACKNOWLEDGEMENTS}

We thank the Région Bretagne and the VCCTL Consortium (NIST) for their contribution to this study. We also would like to extend our thanks to Dr. Nicos Martys (NIST), Dr. Edward Garboczi (NIST), Dr. Jon Martin (NIST) for their constructive comments.

The authors gratefully acknowledge the generous assistance of Aggregate Industries, which provided the concrete truck, laboratory facilities, and concrete materials used in this study. The authors also wish to thank the Sika Corporation for providing the chemical admixtures. 


\section{List of Figures}

Figure 1: Geometrical characteristics of the drum of the used mixing truck and representation of the flow of concrete on the blade of the drum. ............................ 19

Figure 2: View of the truck used, the slump indicator, and the interior of the drum........ 25

Figure 3: View of the ICAR rheometer prototype, vane, and principal dimensions ....... 27

Figure 4: Flow curves obtained with the truck mixer (empty truck, C10 to C14 mixture)

Figure 5: Flow curves obtained with the truck mixer (C20 to C23 mixture) ....................... 29

Figure 6: Flow curves obtained with ICAR rheometer for Series 1 (C10 to C14) .......... 29

Figure 7 : Flow curves obtained with ICAR rheometer for Series 2 (C20 to C23) .......... 30

Figure 8: Typical ICAR rheometer stress growth test results for selected mixtures ......... 31

Figure 9 : Relative plastic viscosity, as defined by the ratio of the measured plastic viscosity with the control mixture plastic viscosity, recorded by the mixing truck and ICAR rheometer. The control mixtures are $\mathrm{C} 10$ and $\mathrm{C} 20$.

Figure 10: Illustration of slope of the flow curves for selected ICAR rheometer

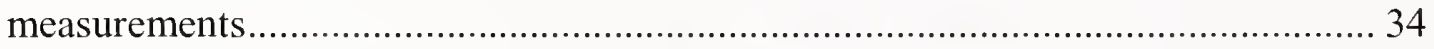

Figure 11: Correlation of plastic viscosity value between ICAR rheometer and truck .... 35

Figure 12: Relative yield values, as defined by the ratio of the measured yield stress with the control mixture yield stress, as recorded by mixing truck, ICAR rheometer, and

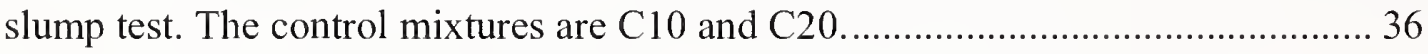

Figure 13: Correlation of yield value between ICAR rheometer and truck..................... 36

\section{List of Tables}

Table 1: Evolution of the technology for mixing concrete ............................................. 5

Table 2: Calculation of shear rates in a blender for cement paste ................................... 10

Table 3: Evolution of the design of mixing truck during the last 100 years..................... 14

Table 4: Summary of some devices designed to control the workability of concrete ...... 20

Table 5: Aggregate particle size distributions …………............................................... 24

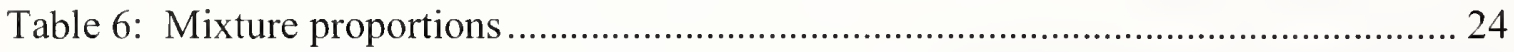

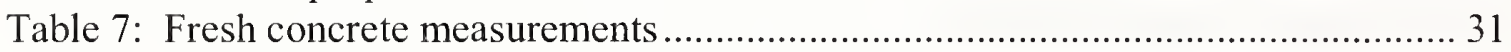




\begin{abstract}
$\underline{\text { Abstract }}$
Fresh concrete properties dictate the performance of the concrete in its hardened state. The measurement of workability is usually done using a simple slump test. This test. although widely used for almost 100 years, does not provide a full picture of the workability or flow properties of fresh concrete. Therefore, many tests [1] were designed to fully characterize concrete. Few are consistently used in the field. The most fundamental are the tests based on rheology, such as the rotational rheometers $[2,3]$. There is a need for a relatively simple test that could be used in the field but that will fully characterize fresh concrete flow properties.
\end{abstract}

The mission of this study was to evaluate the feasibility of using a concrete truck mixer as a rotational rheometer. To succeed, it is necessary that the methodology measure fundamental rheological parameters (plastic viscosity and yield stress) during the mixing process.

This report summarizes the state of the art on concrete truck mixers used as tools to characterize fresh concrete. Then, a short proof of the concept is attempted by using a concrete truck and a rotational rheometer to characterize nine concrete mixtures [4]. The results are presented and discussed. The methodology developed is based on using the truck drum rotation combined with the measurement of the torque induced by the concrete load. This is similar to the typical method of determining the flow behavior in a traditional rotational rheometer, i.e., the Bingham model: the shear rate (or drum rotational speed) versus the shear stress (or torque) was plotted. The slope of the linear relationship is the plastic viscosity and the intercept at zero shear rate is the yield stress. The results of these experiments are discussed and compared with data provided by the ICAR [5] rheometer, a portable rheometer designed for measuring concrete rheology in the field.

The test results indicate that the mixing truck is sufficiently sensitive to detect differences in yield stress, slump, and plastic viscosity. However, the plastic viscosity determined by the truck measurement is not correlated with plastic viscosity results obtained from the ICAR rheometer, while the yield stress determined by the truck measurement correlates with the slump and the ICAR rheometer results. Suggestions are given on how to improve the mixing truck for use as a rheometer. 



\section{Introduction}

During the last 60 years, the ready-mixed concrete industry has experienced tremendous growth worldwide. For example, in the United States approximately 3700 companies operating 10,000 plants provide over two-thirds of the total concrete consumed in the country [6]. Six or seven percent of the companies produce $50 \%$ of the ready-mixed concrete and each operates more than 100 truck mixers. In the USA, concrete is batched and mixed in accordance with ASTM C 94 [7], "Standard Specification for Ready-Mixed Concrete". To ensure high-quality ready mixed concrete, the Truck Mixer Manufacturers Bureau (TMMB), affiliated with the National Ready Mixed Concrete Association (NRMCA), also establishes standards for truck mixers and agitators [8,9].

In addition, the use of highly fluid concretes, the rheology of which cannot be suitably characterized with the slump test (ASTM C 143) alone, has resulted in the emergence of many new methods for characterizing the flow of freshly mixed concrete. A synthesis of more than 61 existing test methods [1] for workability found that available devices vary widely in their geometry, cost, method of operation, and suitability for field use.

To describe concrete flow behavior, both yield stress and plastic viscosity, as defined by the Bingham model, are key properties that should be determined. The Bingham model describes the flow of concrete or any other material as a linear relationship between the shear rate, $\dot{\gamma}$, and the shear stress, $\tau$, as shown in equation 1 .

$$
\tau=\tau_{0}+\mu \cdot \dot{\gamma}
$$

where $\mu$ : plastic viscosity

$\tau_{0}:$ yield stress.

The measurement of these parameters is currently possible only using a rotational rheometer adapted to concrete, such as the BML ${ }^{1}$, CEMAGREF-IMG, BTRHEOM, IBB, Two-Point, ICAR, or Lafarge rheometers $[2,10]$. These rheometers have various geometries but they all have a rotating part, a blade, a cylinder or a plate and a device to measure the torque induced from the material by the shearing action of the moving part. Unfortunately, the cost of these devices (even if very low compared to the cost of the produced concrete) and their complexities, especially compared to the slump test, has mainly restricted the use of rheological measurements to research laboratories.

The idea of measuring rheological properties during mixing is not new [11]. In fact, some existing concrete rheometers are based on this possibility (IBB, Two-Point). These devices operate by measuring the torque induced on a mixing blade rotated at a range of

${ }^{1}$ The name of rheometers used here are as refereed too in the literature. They are not initial of longer names. 
different speeds. Another possibility for measuring concrete flow properties is based on relating the energy data recorded during mixing, as investigated by de Larrard et al. $[12,13]$. These researchers compared the curve of electric power versus mixing time of the concrete with the measurements obtained from the BTRHEOM and were able to provide a correlation function between the two instruments.

A problem with each of these approaches is that they must be calibrated in order to compute test results in fundamental units. The scatter in data from one rheometer to another can reduce the trust an operator has in a given measurement $[2,3]$. Indeed, the slump test has remained the standard tool throughout the world for characterizing the workability of fresh concrete because of the device's simple calibration, which creates little ambiguity or confusion. The slump test, however, only measures a value related to yield stress, which is insufficient for fully describing the flow properties of concrete, especially for special concrete such as self-compacting concrete (SCC). An attempt to modify the slump test to measure plastic viscosity showed the limits of such an approach [14]. A simple and reliable method of rheological characterization adapted to the needs of industry is needed. In particular, few studies exist on the prospect of determining the flow properties of concrete in a mixing truck in transit to a jobsite. To the authors' knowledge, only one paper has been published on this topic [11].

An analysis of the concrete production process shows that the transport phase in a mixing truck, particularly just before discharging concrete from the truck, is the most suitable time to measure rheological properties. To make rheological measurements during the mixing process, the mixing truck must be able to mix the concrete at different speeds to generate a range of shear rates. A mixer in a central plant, despite being considered more efficient than a truck mixer, is not typically capable of operating at different speeds [15, 16].

Most of the plants are equipped with automatic batching systems and controls made possible by the use of microprocessors and computers. Truck mixing and transport rather than central mixing is still the commonly used method of mixing in some countries although, due to better quality control most ready-mixed concrete plants now use trucks only for the transportation of centrally-mixed concrete.

Regarding the process to produce and transport concrete there are two methods:

- The first method, used mainly in North America, United Kingdom (UK) and in Italy, implies that mixing and transporting of concrete is done in the concrete truck. A standardized mixing procedure allows the obtaining of a homogeneous mixture. One of the factors that contributed to the adoption of this method is the long distance that concrete needs to travel from the plant to the job site. It allows more flexibility in the management of the concrete delivery.

- The second method, used in Europe (with the exception of Italy and UK), uses a highly efficient central mixer that ensures the homogeneity of the mixture [17]. The concrete mixing truck is only used as a way to preserve the homogeneity of the mixture and to limit evaporation of water [18]. Nevertheless, there are new trends that are leaning toward using the concrete truck as it is done in North 
America. New trucks are being developed that have two mixing spirals mounted in opposition to increase the mixing speed. They may also have vibration capabilities.

This paper will review all the key issues regarding concrete mixing in relation to the use of a truck mixer as a rotational rheometer. In this report, we will discuss three main themes:

- Overview of concrete mixing: the type of mixers, mixing energy and related factors

- Concrete mixing in a truck: historical evolution, shear stress due to the mixing and rheological measurements

- Preliminary tests and results using a concrete mixer truck and a laboratory rotational rheometer

- Conclusions on the feasibility of a truck as a rheometer and plans for future work 


\section{Concrete mixing}

\subsection{Introduction}

The necessity of mixing concrete has triggered the design of numerous mixing devices (Table 1). These devices could be differentiated by the design of the container and the blades as well by the orientation and the speed of the noving parts.

Several state of the art reports have already been prepared on the various types of mixers [19]. Studies on mixers $[15,16,20,21]$ showed that the performance of the mixing action strongly influences the homogeneity of the mixture, the rheological properties [22] and the microstructure [23] of the concrete.

From these studies, it is clear that, regardless of the geometry or other characteristics of the mixer, two parameters are paramount during a mixing procedure: 1) the energy used and 2) the shear rate imparted to the concrete during mixing. These two parameters are, without doubt, coupled because the shear rate transmitted to the concrete is a result of the energy input in the mixer. Three factors are identified that are related to the shear rate:

- The characteristics of the mixer: container and blade geometry, rotation speed of the container and/or blades

- Behavior of the interface between the material and the mixer: losses by friction or slippage

- Characteristics of the mixture: density and load or total mass of the materials, rheological characteristics (yield stress and plastic viscosity)

The precise quantification of these three factors allows the calculation of the energy balance and to determine the energy that is really transmitted to the materials being mixed. In other words:

$$
\text { Transmitted energy = total mixing energy }- \text { losses }
$$

The loss rate depends on the mixer and the tribological characteristics of the mixtures as well as of the interface between the mixer walls and mixture. 
Table 1: Evolution of the technology for mixing concrete
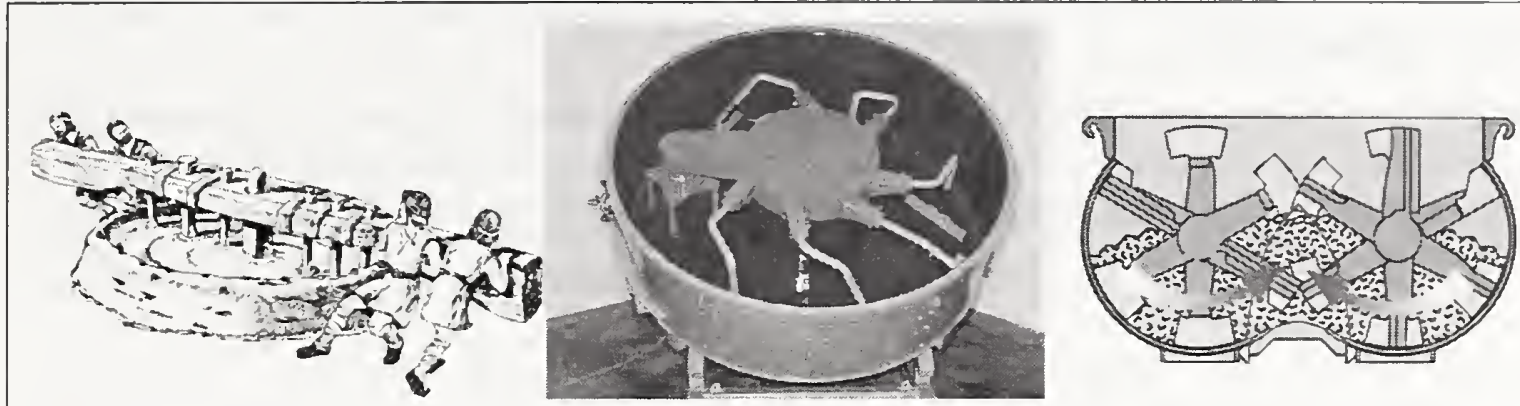

Remains of a Saxon concrete mixer discovered in Britain (left dating from A.D. 700) show that shallow bowls were cut into bedrock [24]. The newest mixers (center, right) are not very different except that the power is furnished by an engine.

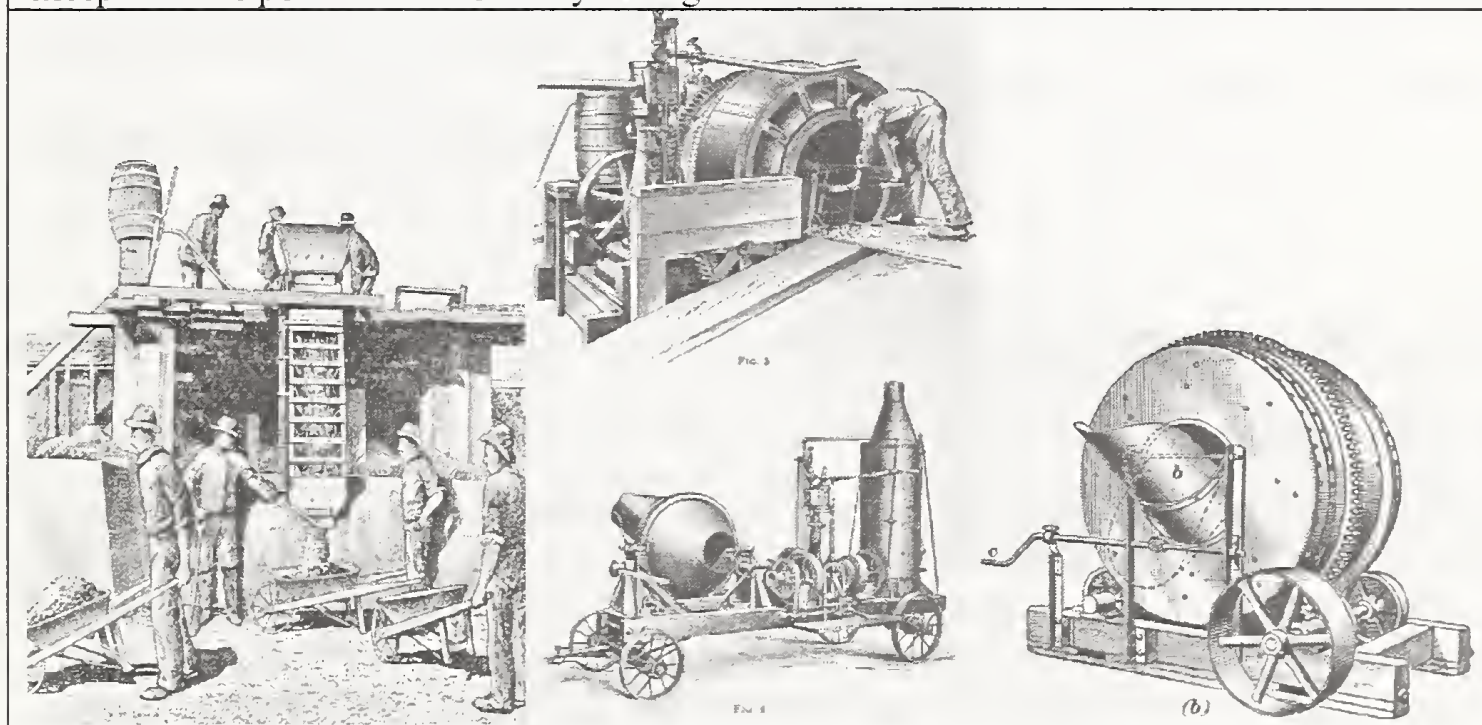

Concrete mixing by portable gravity mixer (1899) [25] is one of the oldest types of concrete mixers (left). At the center and right, mixers based on the rotation of a cylindrical drum. The method for charging and discharging change between the different types of mixers [26].

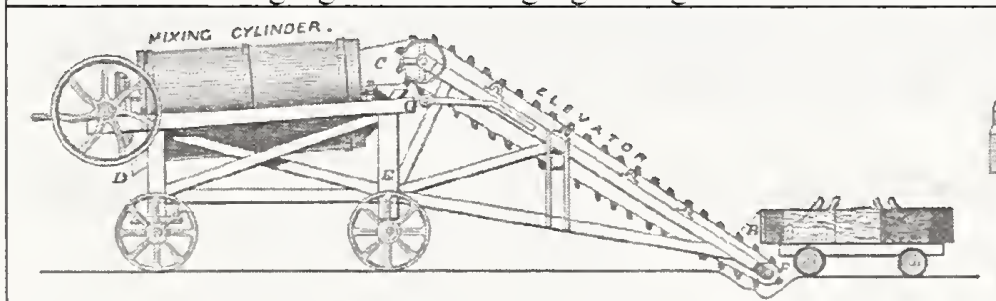

Fig. 100. Le Messterier's Concrete Mactine. Eleration.
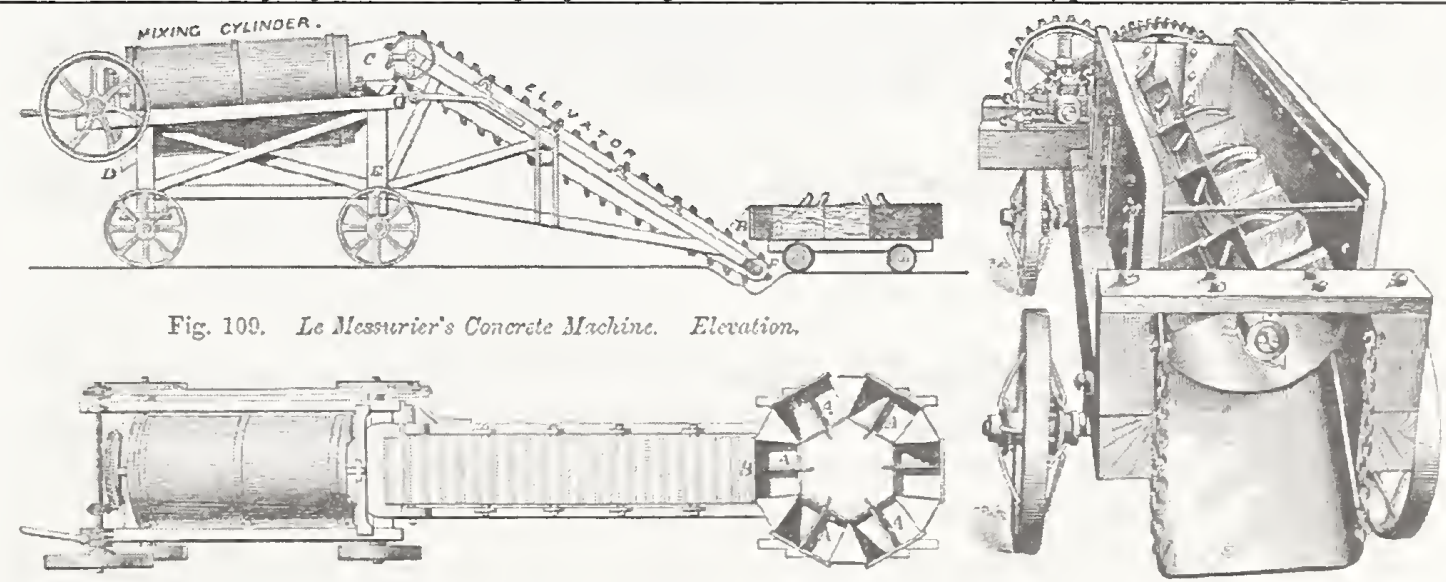

Messurier's concrete machine (used in UK) uses a mixing cylinder [25]. Drake mixer (right picture)is another type of continuous mixer at the same period (late $19^{\text {th }}$ century). 


\subsection{Principal parameters of mixing operation}

\subsubsection{Mixing forces}

The mixing action generates forces that are transmitted through the fluid during mixing to break the structure of agglomerates. In the case of two particles that form a dumbbell, the maximum dispersive force from a steady shear flow of a Newtonian fluid, known as the dispersive force, $\mathrm{F}_{\max }$, is:

$$
F_{\text {max }}=3 \pi \cdot R_{1} \cdot R_{2} \cdot \tau=3 \pi \cdot R_{1} \cdot R_{2} \cdot(\eta \cdot \dot{\gamma})
$$

where $\eta$ is the plastic viscosity and $\dot{\gamma}$ is the shear strain rate (also called the strain gradient) (in s${ }^{-1}$ ). $R_{1}$ and $R_{2}$ are the radii of the particles, and $\tau$ is the shear stress in Pa.

For a non-Newtonian fluid, this equation becomes:

$$
F_{\max }=3 \pi \cdot R_{1} \cdot R_{2} \cdot\left(\tau_{0}+\mu \cdot \dot{\gamma}\right)
$$

where $\tau_{0}$ is the yield stress (in Pa), and $\mu$ is the plastic viscosity (in Pa.s).

\subsubsection{Mixing energy}

Determination of mixing energy can be calculated using various methods that are often similar. We summarize here the methods that are used for cementitious materials. The more basic method consists in recording the power consumed during mixing in watts. A study of the determination of the time to reach a stable (homogeneous) mixture from the power curves shows how this method is implemented [13]. Nevertheless, the power curve is related to the geometry of the mixer, resulting in difficulty in comparing results obtained in different mixers.

The calculation of the mixing energy is the integration of the electrical power used during the mixing time as a function of the mixture volume [13], as shown in Equation 4:

$$
E=\frac{\int_{0}^{/ \Delta t} P_{i} \bullet \Delta t}{3600 \bullet V}
$$

where: $\quad E$ : Total mixing energy per volume of material $[\mathrm{W} \mathrm{h} / \mathrm{L}]$,

$t$ : total mixing time $(\mathrm{h})$,

$\Delta t$ : interval of measurement $[\mathrm{h}]$,

$P_{i}$ : electrical power consumed $[\mathrm{W}]$ and

$V:$ mixture volume [L].

This equation is independent of the mixer geometry and therefore independent of the energy transferred to the mixture. It does not allow the calculation of the mixing performance. 
Another method is to evaluate the mixing energy, $E,[27,28]$ as a function of the mechanical work provided by the mixer during a mixing time $t$ (Equation 5).

$$
E=T \cdot \omega \cdot t
$$

As a first approximation, it could be stated that the torque $T$ is proportional to the rotation speed $\omega$ and the material density $\rho$, as shown in equation 6 :

$$
E=k \cdot \rho \cdot \omega^{2} \cdot t
$$

The coefficient $k$ was experimentally found for a propeller-type mixer to be $k=6.1 \cdot 10^{-8}$ $\mathrm{N} \cdot \mathrm{m} / \mathrm{kg} \cdot \mathrm{m}^{-3} / \mathrm{rad} / \mathrm{s}\left(k=6.4 \cdot 10^{-9} \mathrm{~N} \cdot \mathrm{M} / \mathrm{kg} \cdot \mathrm{m}^{-3} \cdot \mathrm{rpm}\right)$. This is not a universal value as it is dependent on the type of mixer [27].

Equation 5 could be normalized by the mass of the mixture, $M$ (Equation 7):

$$
\frac{E}{M}=\frac{k^{\prime} \cdot \rho \cdot \omega^{2} \cdot t}{\rho \cdot V}=\frac{k^{\prime} \cdot \omega^{2} \cdot t}{V}[\mathrm{~kJ} / \mathrm{kg}]
$$

For a given volume, this equation has the advantage of being only dependent on the mixing time $t$ and the square of the rotational speed, $\omega^{2}$. As reported in ref. [28], the constant $k^{\prime}$ is equal to $6.1 \cdot 10^{-11} \mathrm{~m}^{5} \cdot \mathrm{s}^{-1}$. This constant was obtained experimentally.

It should be noted that during the development of the Two-Point test [29], inspired by the work by Sculion [30], a study was conducted to establish the rheological curve through the measurement of the mixing energy. The main problem found by Tattersall was how to calibrate the system. The torque was calculated using equation 8 :

$$
T=\frac{P_{f}-P_{0}}{\omega}[N . m]
$$

where $\quad P_{f}$ : Power delivered by the mixer during mixing [watts]

$P_{0}$ : Power of the mixer empty [watts]

$\omega$ : Speed Rotation $\left[\mathrm{s}^{-1}\right]$

The evaluation of the losses could be done experimentally by measuring the rheological characteristics of the material with a rheometer and comparing the result with the mixing energy (equation 9) in $[\mathrm{kJ} / \mathrm{kg}]$.

$$
\frac{E}{M}=\frac{k \cdot \bar{\varpi}^{2} \cdot t}{V}
$$


Finally, Padgett [31] showed that the parameter of shear rate is more appropriate than the total mixing energy to describe both mixing and the rheological properties of the material. Therefore, Padgett used an equation relating energy in $[\mathrm{kJ} / \mathrm{kg}]$ to shear rate and plastic viscosity (equation 10):

$$
\frac{E}{M}=\eta \bullet \dot{\gamma} \bullet t
$$

The equation demonstrates that a low shear device can exert the same amount of mixing energy into slurry as a high-shear device provided that the residence time is increased for the low shear device.

The approach is to quantify the mixing energy with equation 11:

$$
E=\omega \cdot t \cdot S \cdot k
$$

where $\quad \omega$ : Rotational speed or rotation per minute

$S:$ shearing area

$k:$ mixer coefficient (depends on the geometry).

It should be noted that a continuous mixer rotates faster $(12.57 \mathrm{rad} / \mathrm{s}$ or $120 \mathrm{rpm})$ than a batch mixer $(2.09 \mathrm{rad} / \mathrm{s}$ or $20 \mathrm{rpm}))$.

In conclusion, because of the great influence of both mixer geometry and the mixed material volume on the effective mixing energy transmitted to the material, it is difficult to derive an equation without undetermined coefficients. Experimentation for each configuration with different geometry and material volume is essential to identify the coefficient that takes into account these parameters.

\subsubsection{Shear rate during mixing}

It was shown [32] that cement-based material plastic viscosity is dependant on the shear rate. For this reason, a summary of the methods to quantify the shear stress imposed on the materials starting from cement paste through mortar to concrete will be presented. It should be noted that in the case of a multi-scale material such as concrete, the influence of the aggregate size distribution (size, shape and volume concentration) is a major component for the evaluation of the shear rate produced by the mixing procedure. This can be explained by the fact that the movement of the coarse aggregates induces a shear stress in the mortar or paste medium. Therefore, the shear rate is not homogeneous in all parts of the material. This non-homogeneity is compounded by factors linked to the geometry and the rotational speed of the mixer.

\subsubsection{Cement paste}

The shear rate of the cement paste in concrete is a major factor that needs to be taken into account. The specific shear rate $[31,33]$ is described by Equation 11 : 


$$
\frac{E}{M}=\eta \cdot \dot{\gamma} \cdot t
$$

where $E$ : Mixing Energy $[\mathrm{kJ} / \mathrm{kg}]$

$M$ : Mass of the material $[\mathrm{kg}]$

$\eta$ : Apparent plastic viscosity of the mixture [Pa s]

$\dot{\gamma}:$ Shear rate $\left[\mathrm{s}^{-1}\right]$

Also, it is possible to determine the shear rate during mixing from the power input measurement [33] using, in the case of a non-Newtonian fluid, the following equation:

$$
P_{v}=\tau \times\left(\dot{\gamma}_{p}\right)=\eta_{a}\left(\dot{\gamma}_{p}^{2}\right)
$$

where

$$
\begin{aligned}
& \tau: \text { Shear stress }\left(\tau=\eta_{a} \cdot \dot{\gamma}_{p}\right)[\mathrm{Pa}] \\
& P_{v}: \text { Power input/unit volume } \\
& \dot{\gamma}_{p}: \text { Shear rate (velocity gradient in the paste) of cement paste }\left[\mathrm{s}^{-1}\right] \\
& \eta_{a}: \text { Apparent plastic viscosity }[\mathrm{Pa} \mathrm{s}] .
\end{aligned}
$$

It is important to note that for non-Newtonian materials the ratio of shear stress to shear rate is not constant but depends on the shear rate at which the measurement was made [33]. Therefore, the apparent plastic viscosity $\eta_{a}$ is defined as the non-Newtonian plastic viscosity.

For plastic and fluid materials the shear rate, or the velocity gradient in the material, $\dot{\gamma}_{p}$, in $[(\mathrm{m} / \mathrm{s}) / \mathrm{m}]$ used to define the flow is:

$$
\dot{\gamma}_{p}=\frac{v}{y}=\frac{\text { relative velocity }}{\text { thickness of paste being sheared }}
$$

Using Equation 13, we obtain :

$$
\dot{\gamma}_{p}=\left(\frac{P_{v}}{\eta_{a}}\right)^{1 / 2}
$$

and for Bingham plastic solids the apparent plastic viscosity may be written as:

$$
\eta_{a}=\frac{\tau}{\dot{\gamma}_{p}}=\frac{\left(\tau_{0}+\eta_{p} \cdot \dot{\gamma}_{p}\right)}{\dot{\gamma}_{p}}
$$

where $\eta_{p}$ : plastic viscosity of cement paste 
Replacing $\eta_{\mathrm{a}}$ with equation 16 expression in Equation 13 , the power input in $\mathrm{W} / \mathrm{mm}^{3}$ is:

$$
P_{v}=\eta_{a}\left(\dot{\gamma}_{p}^{2}\right)=\left(\tau_{0}+\eta_{p \times} \dot{\gamma}_{p}\right) \cdot\left(\dot{\gamma}_{p}\right)
$$

Typical values for $\eta_{a}$ for cement paste range from $0.02 \mathrm{~Pa} \cdot \mathrm{s}$ to $0.2 \mathrm{~Pa} \cdot \mathrm{s}\left(0.2 \cdot 10^{-10}\right.$ $\mathrm{W} \mathrm{s} \mathrm{mm} \mathrm{m}^{-3}$ and $2 \cdot 10^{-10} \mathrm{~W} \mathrm{~s} \mathrm{~mm}^{-3}$ ).

The range of shear rates is then given by:

$$
\begin{aligned}
& \dot{\gamma}_{p}=\left(\frac{0.05}{2.0 \times 10^{-7}}\right)^{1 / 2}=500 \mathrm{~s}^{-1} \\
& \text { to : } \\
& \dot{\gamma}_{p}=\left(\frac{0.25}{0.2 \times 10^{-7}}\right)^{1 / 2}=3500 \mathrm{~s}^{-1}
\end{aligned}
$$

Similar calculations were made in a high shear blender [33].

Table 2: Calculation of shear rates in a blender for cement paste

\begin{tabular}{|l|l|l|l|l|l|l|l|}
\hline Batch & $\begin{array}{l}\text { Power input } \\
\text { assuming } \\
50 \\
\text { efficiency) }\end{array}$ & Cement & Water/Cement & $\begin{array}{l}\text { Volume } \\
\text { paste (L) }\end{array}$ & $\begin{array}{l}\tau_{0} \\
{[\mathrm{~Pa}]}\end{array}$ & $\begin{array}{l}\eta \\
{[\mathrm{Pa} \cdot \mathrm{s}]}\end{array}$ & $\begin{array}{l}\dot{\gamma}_{p} \\
{\left[\mathrm{~s}^{-1}\right]}\end{array}$ \\
\hline $\begin{array}{l}1 \\
\text { (cement I) }\end{array}$ & $200 \mathrm{~W}$ & $400 \mathrm{~g}$ & 0.4 & 0.287 & 32 & 0.13 & $\begin{array}{l}1480- \\
1520\end{array}$ \\
\hline $\begin{array}{l}2 \\
\text { (cement II) }\end{array}$ & $200 \mathrm{~W}$ & $400 \mathrm{~g}$ & 0.5 & 0.327 & 13 & 0.05 & $\begin{array}{l}2220- \\
2510\end{array}$ \\
\hline
\end{tabular}

\subsubsection{Concrete}

For concrete, a study was conducted by the Laboratoire Central des Ponts et Chaussées (LCPC in France) on three types of mixers [13, 34]:

- Pan mixer with non-rotating central blades: 1500 L capacity

- A tilt-up mixer: 2500 L capacity

- A planetary mixer: $150 \mathrm{~L}$ capacity

From the data acquired from this study, they were able to develop a model of the power consumed during mixing 


$$
P(t)=P_{\infty}+P_{d} e^{\left(\frac{-1}{t_{d}}\right)}+\frac{2 P_{m}}{\pi} \times\left(\operatorname{Arctan}\left(\frac{t_{a}-t}{t_{m}}\right)+\frac{\pi}{2}\right)
$$

where $t$ : mixing time

$P(t)$ : Total power consumed

$P_{x}$ : Equilibrium final power after complete mixing.

$P_{d}$ : The power related to the dispersion of the granular mixture in the container of the mixer

$P_{m}$ : Power related to the dispersion of the finest particle.

$t_{a}$ : Delay time able to improve the quality of the fitting curve of the power diagram at initial mixing

$t_{d}$ and $t_{m}$ : Times characterizing the duration of damping rate of each type of power.

The term $P_{x}$ could be related to the rheological characteristics of the materials as described in Equation 20 [12]:

$$
P_{\propto}=P_{f}+C_{m} \cdot \dot{\gamma} \cdot\left(\tau_{0}+\mu \cdot \dot{\gamma}\right)
$$

where $\dot{\gamma}$ : Mean shear rate in the mixer $\left(\mathrm{s}^{-1}\right)$

$C_{m}$ : Parameter having the dimension of a volume $\left(\mathrm{m}^{3}\right)$

$P_{f}$ : Power losses due to the mechanical parts of the mixer

$\tau_{0}:$ Yield stress as measured with BTRHEOM rheometer

$\eta$ : Plastic viscosity as measured with BTRHEOM rheometer.

The second term of Equation 19, $P_{d} e^{\left(\frac{-t}{t_{d}}\right)}$, corresponds to the energy used due to the rapid dispersion of the coarse aggregates. Finally, the third term, $\frac{2 P_{m}}{\pi} \times\left(\operatorname{Arctan}\left(\frac{t_{a}-t}{t_{m}}\right)+\frac{\pi}{2}\right)$, takes into account the energy used for the dispersion of the fine aggregates, i.e., defloculation and/or humidification of the fines.

\subsubsection{Influence of mixing energy}

For a given geometry of the mixer (container and blades). the mixing energy has a considerable influence on the workability of the cement paste. It was established experimentally $[33,34]$ that the mixing energy influences the amount of free water left after mixing as well as the performance of chemical admixtures. This would result in different hydration kinetics leading to different mechanical and durability characteristics

The effects of mixing procedures upon the rheological properties of cement mixes with and without high-range water-reducing admixtures (HRWRA) have been also investigated [35]. In this study, the effects upon yield stress. plastic viscosity and hysteresis were studied using a co-axial viscometer. In the absence of chemical 
admixtures, yield stress and plastic viscosity decreased substantially with increasing intensity of mixing, which caused a breakdown of particulate agglomerates. The mixing procedure had more effect upon the yield stress than upon the plastic viscosity.

According to Equation 12, the energy per mass using the American Petroleum Institute (API) mixing method for a cement slurry is $5.5 \mathrm{~kJ} / \mathrm{kg}$. Orban et al. [27] defined specific mixing energy (SME) as the ratio of the slurry energy per mass and the value corresponding to the API laboratory procedure, i.e., $5.5 \mathrm{~kJ} / \mathrm{kg}$.

Orban showed that an increase of the SME from 0 to 1 results in a clear improvement in the homogeneity of a mixture. A SME between 1 and 2 is optimal as defined by the plateau reached by the rheological properties. For a SME larger than 2, the material properties are worsened. However, Hodne et al. [36] showed that the SME parameter does not characterize all types of slurries.

On the other hand, the increase of the mixing speed from $419 \mathrm{rad} / \mathrm{s}$ (4000 rpm) to 1257 $\mathrm{rad} / \mathrm{s}(12000 \mathrm{rpm})$ results in a 10-fold decrease of the time needed to obtain an optimum plastic viscosity and the yield stress [36].

If SME is used, the results are easier to interpret because they are related to the volume of material and an optimal energy level can be determined to obtain the lower plastic viscosity and yield stress.

Finally, the rheological behavior of cement paste during the first $2 \mathrm{~h}$ is strongly influenced by mixing methods as shown by Yang et al. [23]. She measured the stress response of cement pastes while sheared at a constant shear rate. Cement pastes mixed by hand or by paddle mixer have higher and, with time, more rapidly increasing stresses than those prepared by high energy blender mixing. Agglomerates initially existing in cement powder, and later remaining in the paste due to insufficient mixing, are responsible for the higher value and faster increase in stress. 


\section{Mixing truck concrete}

\subsection{One hundred years of evolution of truck mixers}

This section is an attempt to relate the evolution of concrete truck mixers, some of which are pictured in Table 3. The first on-wheel concrete mixer patented in America [37, 38], and called the Mortar Mixer, was patented on February 9, 1904 by Richard Bodlaender of Breslau, Germany. The front axle and wagon wheels of a cart were replaced by a large drum with paddles inside, and as the horse-drawn vehicle moved along, the drum rolling along the ground would create the mixing action.

A mixer, invented by Alvah Handsel of Wilkes-Barre, Pa., patented on January 12, 1909, employed a hexagonal drum that did not roll along the ground. A coal-fired steam boiler attached to a piston pump powered the mixer, which had a gear train to drive the chain drive. The addition of a power unit was such a gigantic leap over horses that for the next decade, almost nothing further was accomplished.

Finally, the first true concrete truck wasn't called a concrete truck. In fact the related patent is titled "Apparatus for Concrete Work." Records indicate that it was invented by Ackert Bickel of Kansas City, Mo., and it was patented under U.S. Patent No. 1,363,304 in 1920. It had no horses, no steam boiler, a real steering wheel, and an internal combustion engine, albeit with a hand-crank starter sticking out the front of the vehicle. The most notable thing about it, however, is an enormous amount of dead space on the truck bed.

When inventor Charles Ball of Milwaukee received U.S. Patent No. 1,766,584 on June 24, 1930 for his next-generation concrete truck, titled "Mixing and Agitating Machine," it was assigned to Chain Belt Co., also of Milwaukee. During the next 2 years, Ball radically changed the designs for the mixing drum and incorporated them into his patents. For the next 40 to 50 years, the general appearance of the concrete truck didn't change much.

In the 1930s, the demand for concrete trucks was exploding due to increasing highway construction. Roscoe Lee's "Transit Concrete Mixer" invention was an attachment that fit on the back of a standard truck frame and carried a drum mixer that was set in place with a small crane. It was less expensive than a dedicated transit truck, and once the contract was complete, the truck could be refitted with a flatbed, box, or dump to carry other materials. 
Table 3: Evolution of the design of mixing truck during the last 100 years

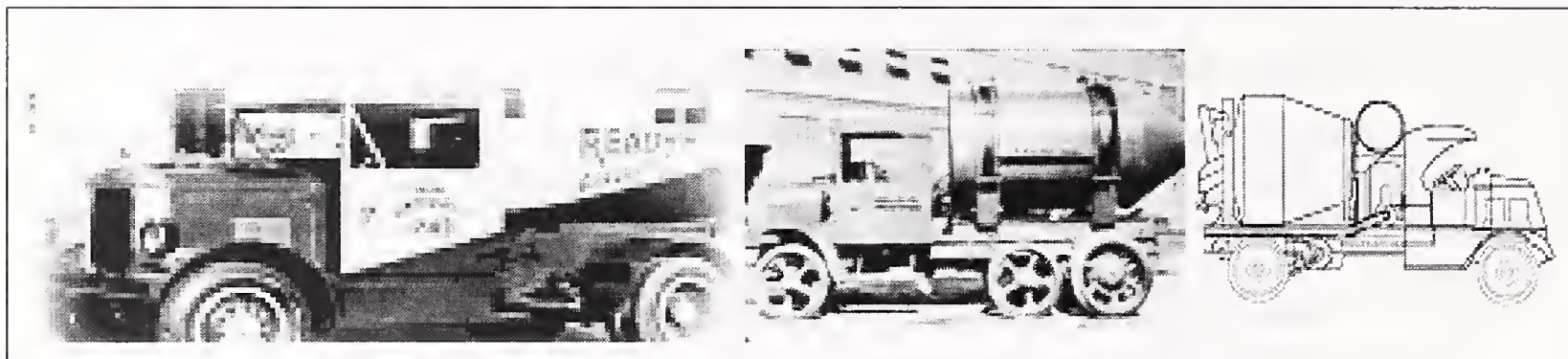

Some of the first mixing trucks patented at the beginning of the $20^{\text {th }}$ century [37].

(1)

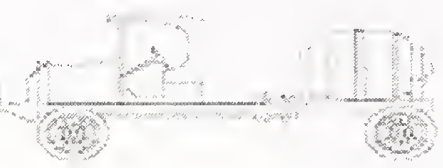

(2)

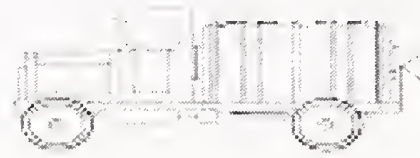

(3)

From the horse-powered to horse power [37]. This 1904 patent combined the mixer and the front wheel on a horse-drawn trailer (1). The first "true" concrete truck patent (2), invented by Ackert Bickel (1920). Milwaukeean Charles Ball's "Mixing and Agitating Machine"(3), (1930).

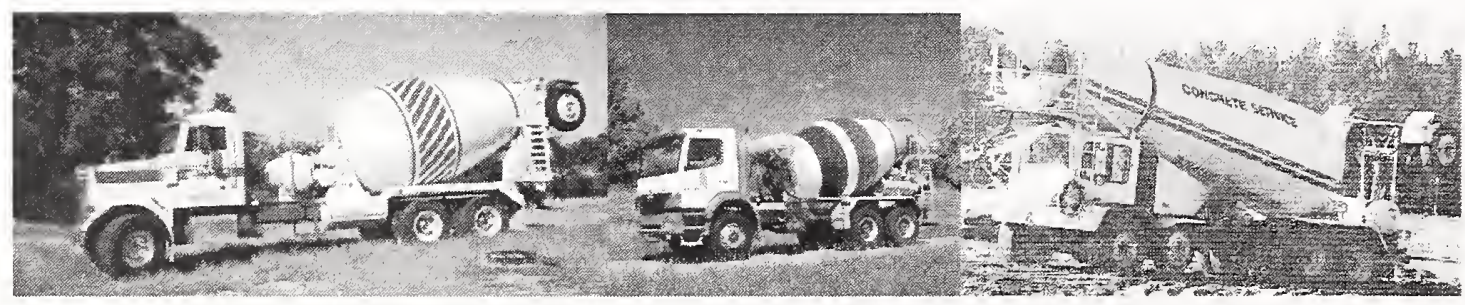

Modern concrete mixing trucks are not much different from those designed in the beginning of the $20^{\text {th }}$ century. [39, 40
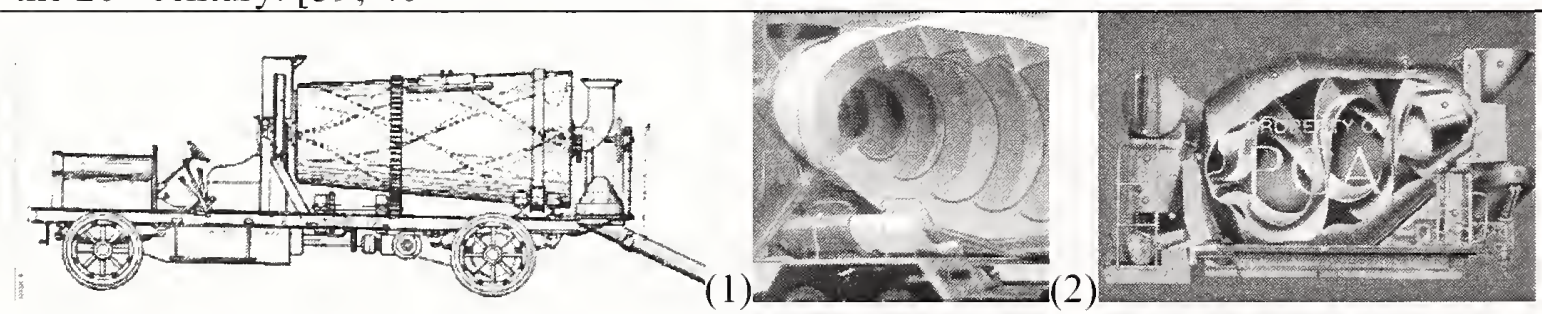

The internal design (1) of Stephen Stepanian truck mixer (1916) [37] is very close to some modern blade designs (2), [41].

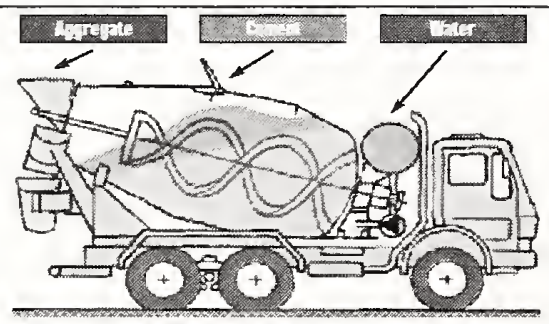

Mixing truck of the last generation in Europe. Raw materials are pre-loaded long before transport and the producer can layer cement on top of the aggregate through the center drum hatch. [42]. 


\subsection{Delivery of Ready Mixed Concrete}

Most of the experimental work related to the delivery of ready mixed concrete, in particular with a truck mixer, found in the literature, has been carried out by Richard D. Gaynor and co-workers of the National Ready Mixed Concrete Association (NRMCA) $[6,7,38,43]$. Its reading should be advised to anyone interested in the topic. A summary regarding the delivery of concrete with a mixing truck from the recommendation given by NRMCA as shown in the box below.

- While ready mixed concrete can be delivered to the point of placement in a variety of ways, the overwhelming majority of it is brought to the construction site in truckmounted, rotating drum mixers. Modern truck mixers have a revolving drum placed with the axis at an angle. Inside the shell of the mixer drum, there are a pair of blades or fins that wrap in a helical (spiral) configuration from the head to the back of the drum. This configuration enables the concrete to mix when the drum spins in one direction and causes it to discliarge when the direction is reversed.

- The mixing pattern imparted by the truck mixer is a lifting of the concrete and then folding or knitting the material on itself.

- Truck mixers come in two forms that differ by the type of discharge: a rear discharge or a front discharge.

- If the truck is used for mixing the load camnot exceed $63 \%$ of its total volume, while for just transportation (central mixed concrete) the truck can be filled to $80 \%$ of its total volume.

- Commonly, the size of a mixer ranges from $1.9 \mathrm{~m}^{3}$ to $9.2 \mathrm{~m}^{3}$. The ASTMC 94, Specification for Ready Mixed Concrete, indicates that the concrete shall be discliarged on the job site within 90 minntes and after less than 300 revolutions after water was added to the cement. The purchaser of the concrete may waive this requirement, when conditions permit.

- The most common mixing sequence used is one minute for the first cubic meter and onefourth of a minute for each additional cubic meter loaded in the truck. In order to increase the production of a centrally mixed plant, most plants will do "shrink mixing." This involves mixing concrete to a point "where the plant slump meter indicates that the desired slump is predictable and then finish mixing on the way to the job site.

- The general cycle time is 70 revolutions to 100 revolutions, however, if the materials have been adequately loaded into the mixer, uniform concrete slionld be obtained within 30 revolutions to 40 revolutions.

- The travel distance of a truck mixer is limited to less than fifteen miles. This limit can be extended by "dry batcling." In this sitnation, the dry materials are added to the truck mixer and water is added at the construction site and "must be added under pressure, preferably at the front and rear of the drum with it revolving at mixing speed, and then the mixing is completed within the usulal 70 to 100 revolutions. 
- When these central mixing and truck mixing are compared, central mixed concrete is the preferred. Some advantages are that the haul cycle time is shortened, wet mixes charge twice as fast as a dry charge, and there is no time loss in adjusting shmup on the job.

- If proper site access is provided for the truck mixer, the concrete can be discharged alongside the designated forms. Chutes are typically used during discharge. The time that is estintated for a full trnck mixer to discharge completely is approximately five minutes.

- Tinck mixers can also discharge their contents into a concrete pump. But the concrete mixture must be adjusted for this type of application.

- The mixer manufacturer's recommend operating speed for mixings in the range between $0.41 \mathrm{rad} / \mathrm{s}(4 \mathrm{rpm})$ and $2.3 \mathrm{rad} / \mathrm{s}(22 \mathrm{rpm})$

\subsection{Factors affecting the quality of concrete in truck mixers}

The goal of mixing concrete is to obtain a uniform mixture with no lumps or agglomeration of materials. Lumps, material balls or agglomerated materials jeopardize structural integrity of a concrete by forming weakened zones and by increasing the permeability [44]. Florida Department of Transportation (FDOT) Standard Specifications for Road and Bridge Construction (2000) Section 346-7.4.1 requires that concrete should be free from lumps and balls of cementitious material. Hence, when lumps are found, concrete batches are rejected. The consequences are disruption of work, costly rework, and loss of valuable time. A study was performed to determine the root causes and the remedies of the formation of lumps and balls in high-slump truck-mixed concrete [44]. Systematic studies on other type of concrete were not found. Based on the findings of this study [44], the following conclusions were drawn:

- Headwater percentage (water added to the mixer before the addition of materials) and initial revolutions have a combined effect on the number of humps and balls produced. The optimum combination was found to be $30 \%$ and $40 \%$ headwater percentage with 90 to 100 initial revolutions at a speed of $1.25 \mathrm{rad} / \mathrm{s}(12 \mathrm{rpm})$.

- The optimum speed (less lumps) at which the materials exit the loader through the chute into the mixing truck (discharge rate) was found to be $90 \mathrm{~kg} / \mathrm{s} \pm 4 \mathrm{~kg} / \mathrm{s}$ (200 $\mathrm{lb} / \mathrm{s} \pm 10 \mathrm{lb} / \mathrm{s})$.

- The size of a concrete load does have an effect on the number of lumps and balls formed, but most trucks have a maximum load size of $6.9 \mathrm{~m}^{3}\left(9 \mathrm{yd}^{3}\right)$ [44] and it is not practical to have a load that is smaller.

- The sieve analysis indicated that most of the concrete humps and balls were similar in gradation and were composed of small coarse aggregates, coarse sand, and cement.

\subsection{Shear rate during mixing: the truck mixer case}

Today, most of the rotating-drum concrete mixers have almost the same geometry. A method found reasonable to determine the shear rate of the concrete during a mixing in a truck was described by Helmuth et al. [33]. 
The drum considered by Helmuth et al. [33] had a capacity of $7.5 \mathrm{~m}^{3}$, with a drum radius, $R$, of $1.20 \mathrm{~m}$. The maximum drum speed, $n$, was $1.74 \mathrm{rad} / \mathrm{s}(16.66 \mathrm{rpm} \text { or } 0.278 \mathrm{rps})^{2}$. The tangential velocity of concrete in the drum during mixing is [33] calculated using Equation (21):

$$
V_{t-m}=R \cdot n=1.20 \cdot 1.74=2.1 \cdot \mathrm{m} / \mathrm{s}
$$

where $n$ in $\mathrm{rad} / \mathrm{s}$ and $R$ in $\mathrm{m}$

The truck drum used is inclined at a small angle $\left(12.5^{\circ}\right)$, to allow the concrete to slide to the front of the drum during mixing. The front of the drum is located behind the driver's seat (Figure 1). Along the length of the drum, a blade is attached perpendicular to the side of the drum, making a relative angle, $\theta$, with the axis of the drum. This angle determines the pitch of the spiral made by the blades and ranges from $55^{\circ}$ to $70^{\circ}$. The average value of the cotangent of the angle can be calculated as follows:

$$
\operatorname{cotan}(\theta)=\frac{\frac{1}{\tan 55}+\frac{1}{\tan 70}}{2}=0.532
$$

This value is used to calculate the velocity, $\mathrm{V}_{\mathrm{c}-\mathrm{m}}$, of the concrete inside the drum as it moves forward due to combined effect of the blades and the drum rotation, as shown in equation 22 .

$$
V_{c-m}=V_{t-m} \cdot \cot a n \theta=2.1 \cdot 0.532=1.11 \cdot \mathrm{m} / \mathrm{s}
$$

An approximate value of the shear rate in the concrete, $\dot{\gamma}_{c}$, can be calculated using equation 23:

$$
\dot{\gamma}_{c}=\frac{\left(\frac{\delta}{t}\right)}{y}=\frac{\text { relative velocity }}{\text { thickness of the sheared concrete }}
$$

where $\quad \delta$ : side length of the considered element of concrete (Figure 2)

$y$ : the displacement during the time interval $t$

$t$ : time required for the displacement of the considered element of concrete.

For example, if $\delta$ is $0.06 \mathrm{~m}$, with a $V_{c-m}$ of $1.11 \mathrm{~m} / \mathrm{s}$, then the interval $t$ is equal to $0.06 / 1.11$ or $0.054 \mathrm{~s}$ and the shear rate:

These data were provided without uncertainty by the manufacturer of the truck. 


$$
\dot{\gamma}_{c}=\frac{\left(\frac{0.06}{0.054}\right)}{0.06}=18.51 \mathrm{~s}^{-1}
$$

There are other regions of higher shear rates between the nearly static material along the blade at the shell and these flowing elements. However, as Helmuth et al. [33] explain, it can be estimated that the maximum shear rate applied to concrete in the drum does not exceed $30 \mathrm{~s}^{-1}$. 


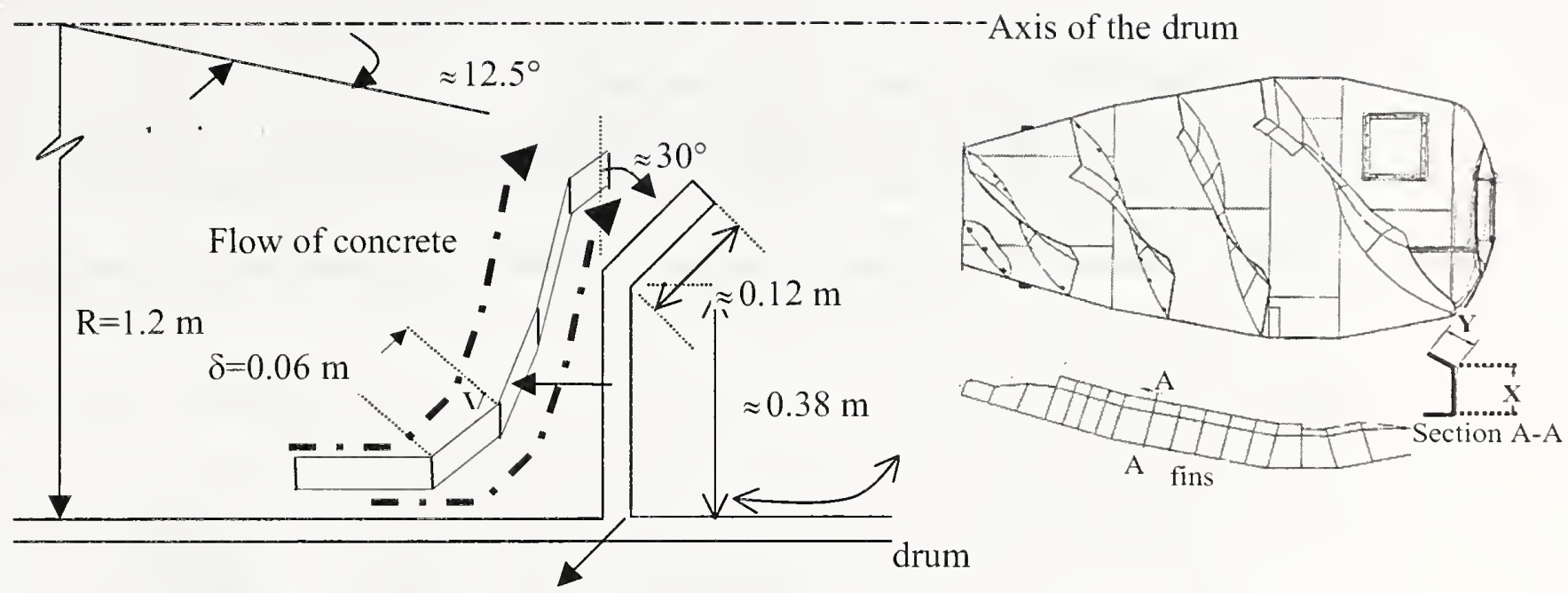

$\mathrm{V}_{\mathrm{t}}$ : tangential speed of the drum

a - Flow of plastic concrete relative to blades during mixing. The concrete flow was modelled as continuous discrete finite elements as explained in the ref. [33]. The square elements have $\delta$ $=0.06 \mathrm{~m}$ sides. The higher shear rate is certainly localized at the angled end of the blade.

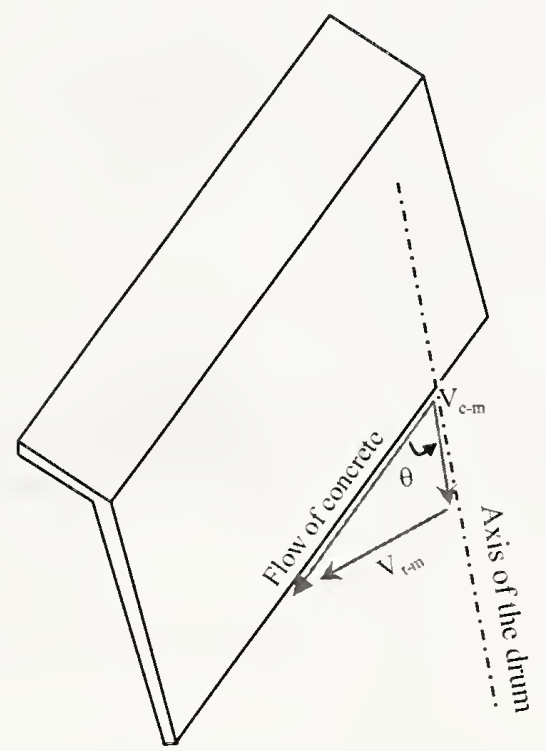

$\mathrm{b}-\mathrm{V}_{\mathrm{c}-\mathrm{m}}$ : Speed of the concrete entering in the drum (mixing)

$\mathrm{V}_{\mathrm{t}-\mathrm{m}}$ : Tangential velocity of the blade during mixing $\operatorname{tg}(\theta)=\frac{V_{t-m}}{V_{c-m}}$

Figure 1: Geometrical characteristics of the drum of the used mixing truck and representation of the flow of concrete on the blade of the drum. 


\subsection{Rheological measurement in a mixing truck}

Since 1929, several patents concerning the workability measurement of concrete directly in the truck mixer were submitted. A summary of the major devices is given in Table 4 .

Table 4: Summary of some devices designed to control the workability of concrete

\begin{tabular}{|c|c|c|c|c|}
\hline Patent & Authors & Title & $\begin{array}{l}\text { Description } \\
\text { (As quoted from the Patent) }\end{array}$ & $\begin{array}{l}\text { Illustration of the concrete device } \\
\text { testing. }\end{array}$ \\
\hline 2002 & $\begin{array}{l}\text { Construction } \\
\text { Equipment } \\
\text { Parts Inc. }\end{array}$ & Slump meter & $\begin{array}{l}\text { The concrcte slump meter indicates the } \\
\text { slump of the concrete by reading the } \\
\text { hydraulic pressure required to turn the } \\
\text { drum. This pressure remains } \\
\text { reasonably constant for a wide range of } \\
\text { load sizes; the only requiremcnt being } \\
\text { that the mixing blades be fully covcred. } \\
\text { The pressurc requircd to turn a drum at } \\
\text { a given slump will be different for each } \\
\text { mixcr becausc of differences in brand, } \\
\text { size, agc, and drive ratios. This requires } \\
\text { the slump indicator to be calibrated for } \\
\text { cach mixer it is installcd on. }\end{array}$ & \\
\hline $\begin{array}{l}6.227 .039 \mathrm{~B} 1 \\
\text { (May } 8,2001)\end{array}$ & $\begin{array}{l}\text { Mosh Te'cni } \\
{[45]}\end{array}$ & $\begin{array}{l}\text { System and method } \\
\text { for controlling } \\
\text { concrete production }\end{array}$ & $\begin{array}{l}\text { The systcm comprising, a surface in } \\
\text { contact with part of a mass of concrete } \\
\text { mix. A shearing plane crossing through } \\
\text { concretc mass, and at least onc sensor } \\
\text { which measures the force which is } \\
\text { transferred to said surface by concrete } \\
\text { mass. }\end{array}$ & . \\
\hline $\begin{array}{l}4,900,154 \\
\text { Feb. } 13,1990\end{array}$ & $\begin{array}{l}\text { Waitzinger } \\
\text { and al. [46] }\end{array}$ & $\begin{array}{lr}\text { Concretc } & \text { mixer } \\
\text { having means } & \text { for } \\
\text { determining } & \text { the } \\
\text { consistency } & \text { of } \\
\text { concrete } & \text { mixing } \\
\text { therein } & \end{array}$ & $\begin{array}{l}\text { A concretc mixer is disclosed having a } \\
\text { mixing drum and a drag body is } \\
\text { mounted in the drum which has a drag } \\
\text { surface positioned to, at least partially, } \\
\text { come into contact with concrete in the } \\
\text { drum during a measuring phase in the } \\
\text { concretc mixing operation. A hydraulic } \\
\text { driving circuit is provided to oscillate } \\
\text { the drag body at lcast during the } \\
\text { measuring phase. A pressure sensor is } \\
\text { conneeted in the hydraulic driving } \\
\text { circuit for measuring the actual } \\
\text { pressure value in the hydraulic driving } \\
\text { circuit, which is indicative of the flow } \\
\text { resistanec on the drag surface during } \\
\text { the measuring phasc of the mixing } \\
\text { operation. }\end{array}$ & $\begin{array}{l}\text { Partially sectioned side view of a concrete mixer } \\
\text { according to a first embodiment of the invention. }\end{array}$ \\
\hline $\begin{array}{l}3,924,447 \\
\text { Dec. } 91975\end{array}$ & $\begin{array}{l}\text { E. Garison } \\
{[47]}\end{array}$ & Slump indicator & $\begin{array}{l}\text { A slump indicator includes a gencrally } \\
\text { flat base blade for attachment to the } \\
\text { exterior side surfacc of the drum, a } \\
\text { shaft rotatably attached to the base } \\
\text { plate and extending into the drum, a } \\
\text { paddle mounted on the end of the shaft } \\
\text { for movement by the wet mix. The } \\
\text { system is fitted with an indicator } \\
\text { (calibratcd with the slump) able to } \\
\text { indicate the resisting of the shaft during } \\
\text { the rotation. }\end{array}$ & \\
\hline
\end{tabular}




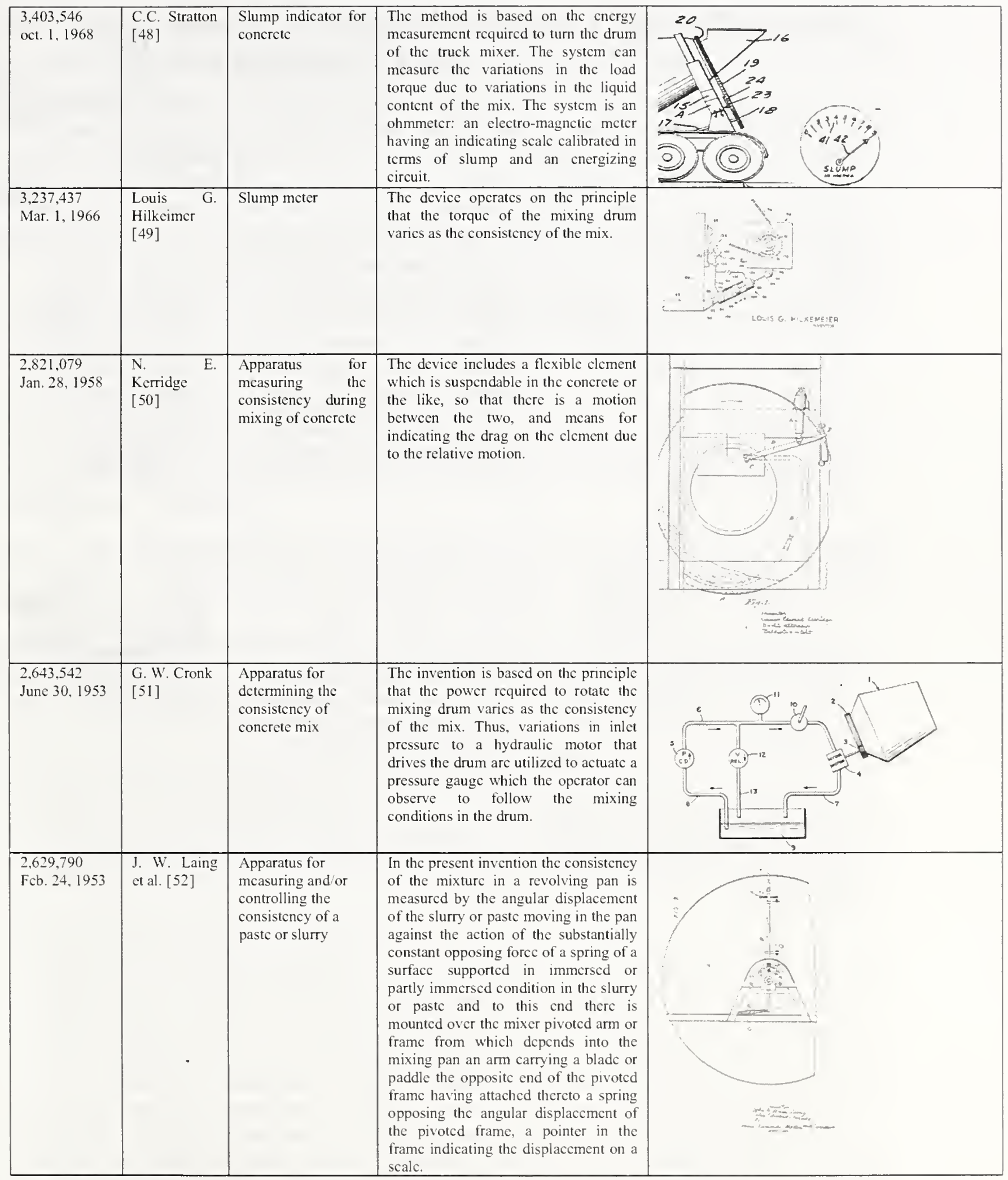




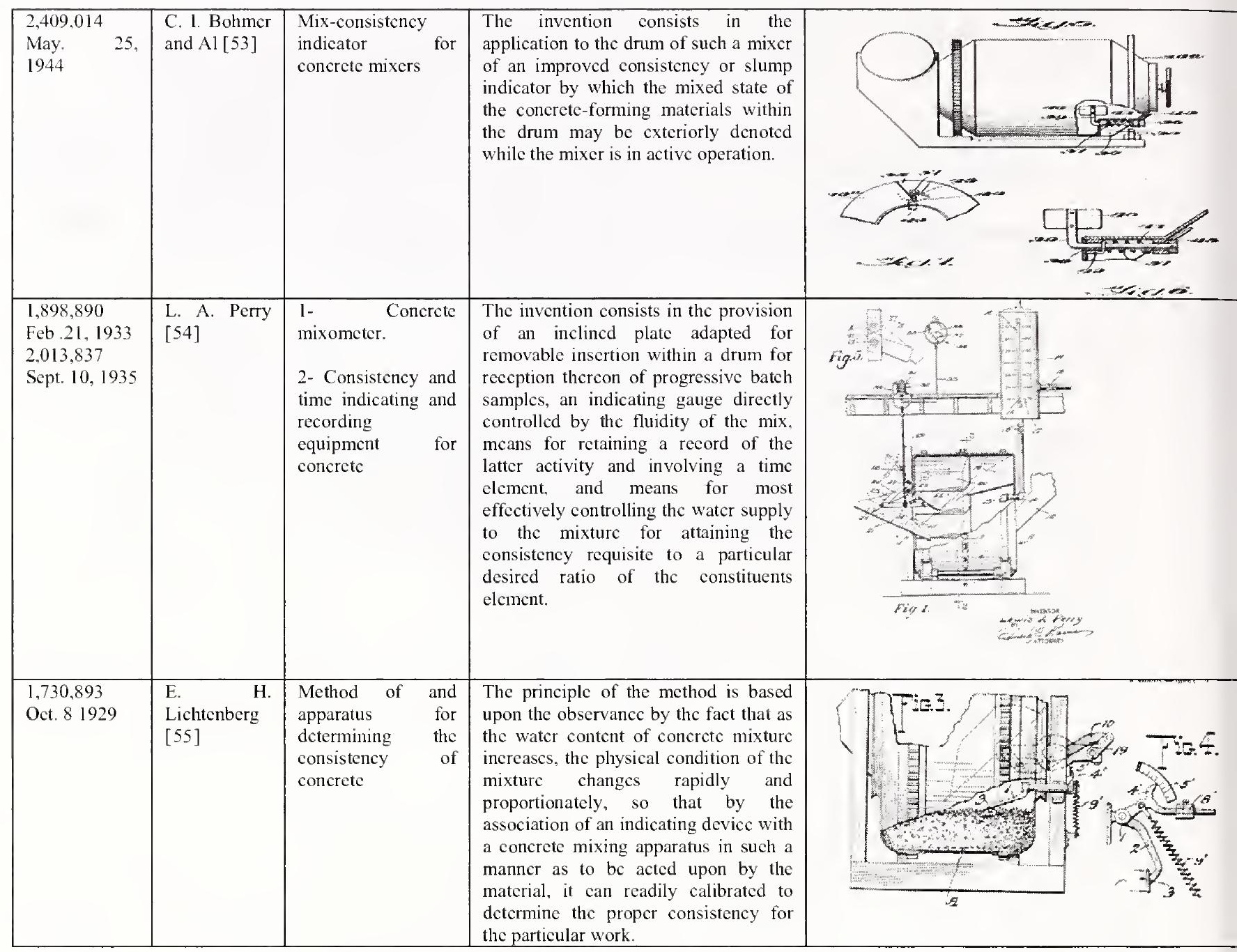

None of proposed tests relate rheological properties as defined by the Bingham model or any other rheological models to the measures obtained with the patented devices. They all attempt to relate to workability as defined by the slump test. This limits their applicability especially with concretes such as self compacting concrete (SCC) as the plastic viscosity is ignored.

Measuring rheological properties of a concrete in a mixing truck was investigated for the first time by J. A. Dackzko [11]. In this limited study, two high-fluidity concrete mixtures were proportioned and tested. Both mixtures composition only differed by the presence or absence of plastic viscosity modifier admixture (VMA). The main finding of this investigation was the apparent good correlation between the flow curve obtained with an IBB rheometer [56] and a truck mixer equipped with a slump meter. The slump meter can measure the hydraulic pressure to turn the drum. A minimum of three pressure readings at three separate drum speeds were obtained. In this way, drum speed would relate to impeller speed in the concrete rheometer, which relates to shear rate in the Bingham model, and the pressure reading would relate to the torque measurement of the rheometer, which relates to shear stress. 


\section{Measurement of Workability of Fresh Concrete during the Mixing Operation in the Field}

Considering the state of the art presented above, the main objective of this study was to evaluate the workability of fresh portland cement concrete while it was still in the mixing truck by determining fundamental rheological parameters (plastic viscosity and yield stress). Nine concrete mixtures with different values of yield stress and plastic viscosity were tested in a concrete truck. The measurements made with the truck were based on the typical method of determining the flow behavior in a traditional fluid rheometer; that is, the shear rate in the mixing truck was swept from high to low by varying the rotation speed of the drum. The results of these experiments are discussed and compared with data provided by the ICAR rheometer [5], a portable rheometer designed for measuring concrete rheology in the field. The test results indicate that the mixing truck equipment is sufficiently sensitive to detect differences in yield stress, slump, and plastic viscosity. However, the plastic viscosity determined by the truck measurement did not correlate with plastic viscosity as measured by the ICAR rheometer, while the yield stress determined by the truck measurement did correlate well with the measured slump and the ICAR rheometer results. Suggestions are given on how to improve the mixing truck for better use as a rheometer.

\subsection{Experimental Program}

\subsubsection{Materials}

The cementitious materials used in all mixtures consisted of an ASTM C 150 Type I portland cement with a Blaine specific surface of $466.6 \mathrm{~m}^{2} / \mathrm{kg}$ and a density of 3050 $\mathrm{kg} / \mathrm{m}^{3}$ and a ground granulated blast furnace slag. The two aggregates were a natural sand denoted "La Plata" and a coarse aggregate denoted "Brandywine". The sand had a maximum size of $3 \mathrm{~mm}$ and consisted of $2.8 \%$ by mass of particles with dimensions smaller than $0.15 \mathrm{~mm}$ (Sieve analysis listed in Table 5).

All admixtures were commercially available products. All concrete mixtures incorporated a water-reducing and retarding admixture based on a sodium salt of organic acid mixture and with a specific gravity of 1.2. The high-range water-reducing admixture (HRWRA) was a polycarboxylate-based admixture with a specific gravity of 1.1. A plastic viscosity-modifying admixture was also used. 
Table 5: Aggregate particle size distributions

\begin{tabular}{|c|c|c|c|}
\hline $\begin{array}{c}\text { US } \\
\text { Standard sieve }\end{array}$ & $\begin{array}{c}\text { Mesh Size } \\
{[\mu \mathrm{m}]}\end{array}$ & $\begin{array}{c}\text { Cumulative mass retain \% } \\
\text { Coarse aggr. } \\
\text { «Brandywine }{ }^{\star *} \\
\# 67 \text { gravel }\end{array}$ & $\begin{array}{c}\text { Cumulative retain \% } \\
\text { Sand } \\
\text { "La Plata» } \\
\text { Sand }\end{array}$ \\
\hline 1 in & 25000 & 0 & \\
\hline $3 / 4$ in & 19000 & 0.6 & \\
\hline $1 / 2$ in & 12500 & 13.9 & \\
\hline $3 / 8$ in. & 9500 & 28.4 & 0 \\
\hline$\# 4$ & 4750 & 46.1 & 0.8 \\
\hline$\# 8$ & 2360 & 79.3 & 10.5 \\
\hline$\# 16$ & 1180 & 94.6 & 23 \\
\hline$\# 30$ & 600 & 97.37 & 48.2 \\
\hline$\# 50$ & 300 & & 85.5 \\
\hline$\# 100$ & 150 & & 97.2 \\
\hline$F M$ & & & 97.3 \\
\hline
\end{tabular}

\subsubsection{Mixture Proportions}

Two distinct control mixtures of concrete - with the same types of materials but with different proportions - were used in the experimental program. As summarized in Table 6 , the two control mixtures were denoted $\mathrm{C} 10$ and $\mathrm{C} 20$. These control mixtures were subsequently modified by using a high-range water-reducing admixture to increase slump (C11, C12, C13, C21, C22), incorporating a plastic viscosity-modifying admixture to increase plastic viscosity (C14), or adding water to increase slump (C23). A total of nine concrete mixtures were tested in this study.

Table 6: Mixture proportions

\begin{tabular}{|c|c|c|c|c|c|c|c|c|}
\hline \multirow[b]{3}{*}{ Groul i Ory Drot } & & \multicolumn{3}{|c|}{$\begin{array}{l}\text { First Concrete Batch } \\
(50 \% \text { Capacity })\end{array}$} & \multicolumn{4}{|c|}{$\begin{array}{l}\text { Second Concrete Batch } \\
(100 \% \text { Capacity) }\end{array}$} \\
\hline & & $\mathrm{C} 10$ & $\mathrm{C} 11 \mathrm{C} 12 \mathrm{C} 13$ & $\mathrm{C} 14$ & $\mathrm{C} 20$ & $\mathrm{C} 21$ & $\mathrm{C} 22$ & $\mathrm{C} 23$ \\
\hline & $\mathrm{kg} / \mathrm{m}^{3}$ & 1099.4 & $\leftarrow$ Constant $\rightarrow$ & & +640.4 & & Consta & int $\rightarrow$ \\
\hline Sand (Oven Dry) & $\mathrm{kg} / \mathrm{m}^{3}$ & 774.0 & $\leftarrow$ Constan & $t \rightarrow$ & +1042.8 & & -Const & ant $\rightarrow$ \\
\hline Water (Free and Absorbed) & $\mathrm{kg} / \mathrm{m}^{3}$ & 145.8 & $\leftarrow$ Constan & $t \rightarrow$ & +157.0 & & -Cons & $\tan t \rightarrow$ \\
\hline Cement & $\mathrm{kg} / \mathrm{m}^{3}$ & 163.7 & $\leftarrow$ Constant & & +222.5 & & -Const & ant $\rightarrow$ \\
\hline Slag & $\mathrm{kg} / \mathrm{m}^{3}$ & 163.2 & $\leftarrow$ Constant & & +223.1 & & -Cons & $\tan t \rightarrow$ \\
\hline Set Retarder & $\mathrm{L} / \mathrm{m}^{3}$ & 0.656 & $\leftarrow$ Constant & & +1.0 & & -Const & ant $\rightarrow$ \\
\hline HRWRA & $\mathrm{L} / \mathrm{m}^{3}$ & 0 & $+1.4+1.4+0.6$ & & & +4.0 & +4.0 & \\
\hline VMA & $\mathrm{L} / \mathrm{m}^{3}$ & 0 & & +0.2 & & & & \\
\hline Testing Time & $\mathrm{h}$ & 0.5 & $\begin{array}{lll}1.0 & 1.5 & 2.0\end{array}$ & 2.4 & 0.5 & 1.0 & 1.6 & 2.1 \\
\hline Temperature & ${ }^{\circ} \mathrm{C}$ & 18 & 19.520 & 21 & 29.5 & 30 & 31 & 31 \\
\hline Slump & $\mathrm{mm}$ & 70 & $\begin{array}{lll}110 & 170 & 240\end{array}$ & 150 & 60 & 120 & 60 & 40 \\
\hline
\end{tabular}

The water quantity calculations take into account the initial moisture content of the aggregates.

\subsection{Rheometers}

\subsubsection{Using the mixing truck as a rheometer}

To transform a truck mixer into a rheometer requires that at least two quantities be measured: the rotational speed of the drum and the power consumption or torque induced by the concrete during the rotation. To obtain both the yield stress and the plastic 
viscosity it is necessary to obtain more than one set of points (speed of rotation, power/torque). The proposed methodology requires the measurement of the power during mixing, the load volume, the mass of concrete, and the shear rate in the concrete, which is deduced from the drum rotational speed and geometrical characteristics.

The values of these two variables (power and shear rate) at different speeds may be plotted against each other. The slope of this resulting curve according to the Bingham model will give the plastic viscosity and the intercept at zero shear rate will give the yield stress. The concrete truck mixer used (Figure 2) was fitted with a device capable of measuring the oil pressure to turn the drum (slump meter). The drum speed measurements were manually made by two persons using a stopwatch. The Bingham test involves sweeping shear rates from highest to lowest and measuring the stress at various shear rates. Therefore, the drum was turned at the highest possible speed $1.67 \mathrm{rad} / \mathrm{s}(16 \mathrm{rpm})$ and then gradually decreased in discrete steps to zero while the oil pressure was measured.

The calculation method to determine the shear rate in the drum from the speed and the truck geometrical characteristics was developed previously on section 2.2.3 and in Ref. [33].

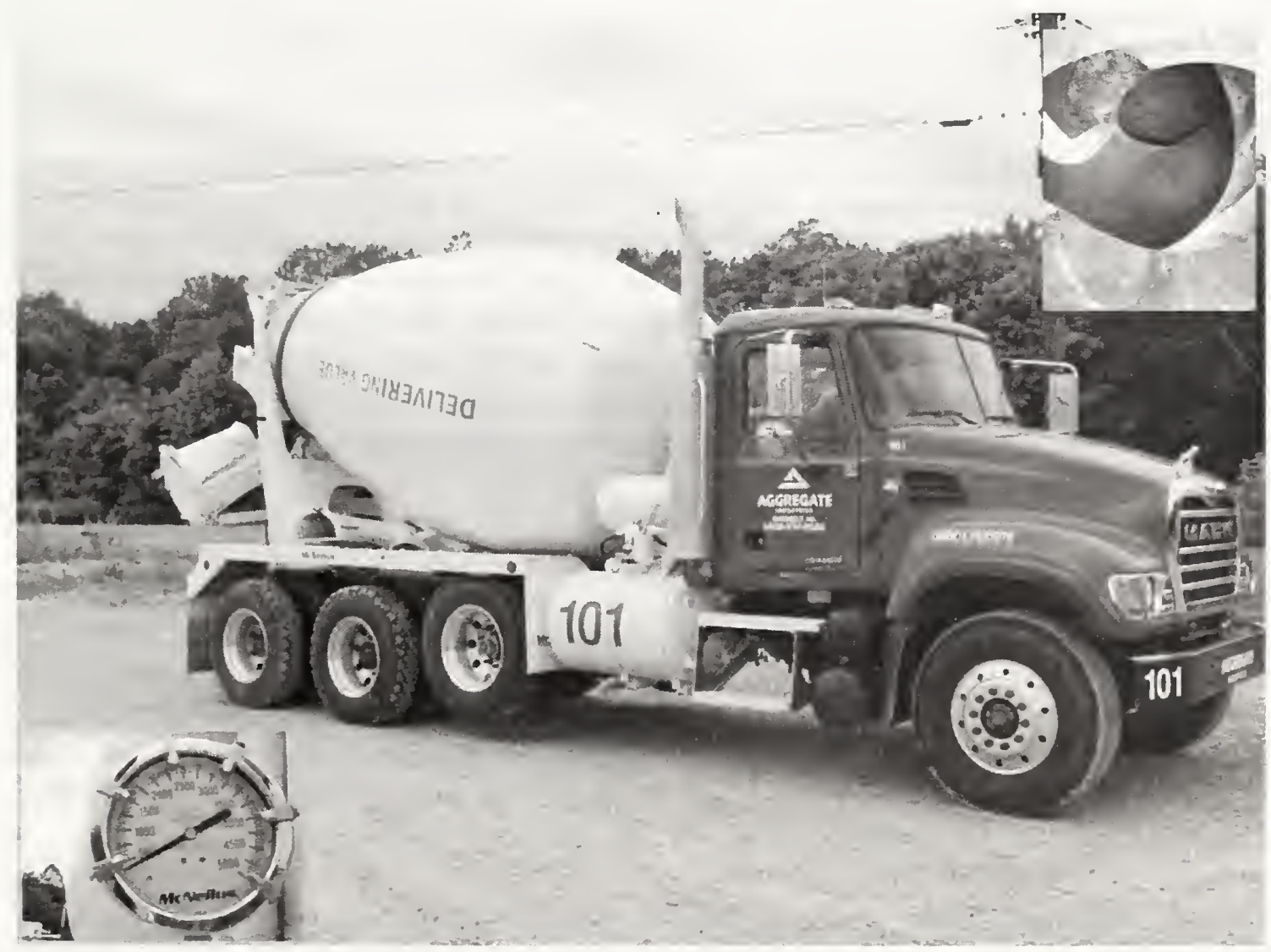

Figure 2: View of the truck used, the slump indicator, and the interior of the drum 


\subsubsection{ICAR Rheometer}

The ICAR rheometer, shown in prototype form in Figure 3, is a portable rheometer for fresh concrete. The device utilizes a four-bladed vane that is immersed into the concrete sample and rotated at a series of fixed speeds. The entire rheometer is approximately the size of a hand-drill and can be either operated by hand or secured into a fixed position above a standard container.

For each concrete mixture, the ICAR rheometer was used to perform a stress growth test and to measure a flow curve. In the stress growth test, the vane was rotated at a constant speed of $0.16 \mathrm{rad} / \mathrm{s}(0.025 \mathrm{rps})$ while the torque was measured. The peak torque was recorded as an approximation of the yield stress as discussed in Ref. [57, 58]. After this peak torque was reached, the flow curve was then measured. The vane was first rotated at a speed of $6.3 \mathrm{rad} / \mathrm{s}(1.0 \mathrm{rps})$ for a breakdown period of $25 \mathrm{~s}$. Torque measurements were then recorded for five speeds ranging in descending order from $6.3 \mathrm{rad} / \mathrm{s}$ to $1.3 \mathrm{rad} / \mathrm{s}$ (1.0 rps to $0.2 \mathrm{rps}$ ). The resulting data were analyzed based on the Bingham model, whereby a straight line was fit to the plot of torque, $T(\mathrm{~N} \cdot \mathrm{m})$, versus rotation speed, $N$ $(\mathrm{rad} / \mathrm{s})$ :

$$
T=Y+V N
$$

The intercept, $Y(\mathrm{~N} \cdot \mathrm{m})$, and the slope, $V(\mathrm{~N} \cdot \mathrm{m} \cdot \mathrm{s})$, of this line were considered to be related to yield stress and plastic viscosity, respectively. Due to the geometry of this rheometer, it is difficult to determine the shear rate analytically in fundamental units [5].

The concrete was placed in a $410 \mathrm{~mm}$ diameter container and filled to a height of 390 $\mathrm{mm}$, as shown in Figure 3. The vane, which measured $130 \mathrm{~mm}$ in diameter and $130 \mathrm{~mm}$ in height, was positioned in the center of the concrete sample, resulting in a gap size of $140 \mathrm{~mm}$ between the vane and the sidewalls and a gap of $130 \mathrm{~mm}$ above and below the vane. 

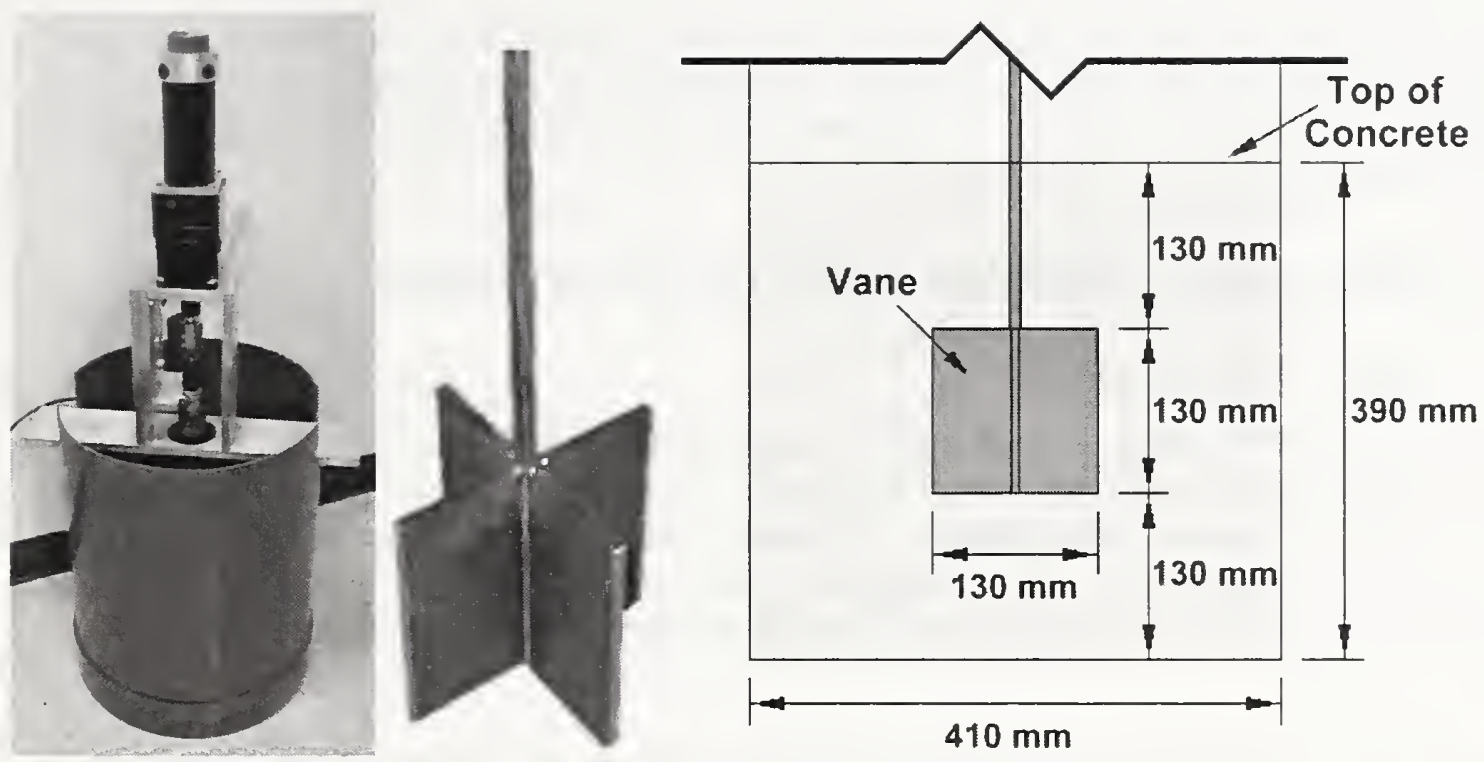

Figure 3 : View of the ICAR rheometer prototype, vane, and principal dimensions

\subsection{Testing Procedure}

The truck with an empty drum was tested initially by measuring the oil pressure versus the rotation speed. This procedure, which was done only once, is shown in Figure 4. It was not possible to measure pressure below $3.44 \mathrm{MPa}(500 \mathrm{psi})$, therefore, preventing the measurement of more than 2 data points.

The concrete was mixed in the central plant mixer for $10 \mathrm{~min}$ and then transferred to the concrete truck mixer. For the first set of tests ( $\mathrm{C} 10$ to $\mathrm{C} 14)$, the truck was filled at $50 \%$ of its maximum capacity, and then more concrete was added on top for the second set (C20 to $\mathrm{C} 23$ ) to reach $100 \%$ of its maximum capacity. The purpose on this sequence was to determine the influence of the load on the results. Due to the progressive setting of the concrete, it was not possible to really detect the influence of load volume influence on the results.

After loading, the truck was moved to the laboratory location: therefore, the first laboratory test on the concrete began $30 \mathrm{~min}$ after the first contact of water and cement. The truck drum turned about 100 revolutions during the transport of the concrete between the central plant and the laboratory. For each mixture, a small volume of concrete was discharged from the truck for testing with the ICAR rheometer and the slump test. These tests were conducted concurrently with the measurements from the truck. The temperature of the concrete was also recorded.

After a set of measurements, the concrete was modified by incorporating an admixture or adding water (see table 1). The concrete was then remixed in the truck and tests were repeated. Five tests were conducted in the first set of tests (C10 to $\mathrm{C} 14)$ and four tests were conducted in the second set of tests (C20 to C23).

To use the truck as a rheometer, the highest speed of the drum (1.74 rad/s or $16.66 \mathrm{rpm})$ was maintained for 10 revolutions while the oil pressure was recorded. The speed of the 
drum was then reduced in increments of $0.21 \mathrm{rad} / \mathrm{s}(2 \mathrm{rpm})$. The oil pressure and speed were recorded at each increment of speed. These measurements produced the curve of oil pressure (related to the torque) vs. rotational speed used to calculate the yield stress and plastic viscosity.

\section{Results and Discussion of the experimentation}

\subsection{Concrete Test Data}

The fresh concrete measurements are summarized in Table 7. The flow curves obtained from truck measurements are shown in Figures 4 and 5, while the flow curves obtained from the ICAR rheometer are shown in Figures 6 and 7. The values of the yield stress and plastic viscosity are deduced from these flow curves, as described by the Bingham model, by calculating the intercept of the linear fit for the yield stress and the slope as the plastic viscosity.

In general, the linear fit of the data for the ICAR rheometer is excellent, as indicated by an average $R^{2}$ value of 0.965 for the nine flow curves. Typical stress growth test plots of torque versus time from the ICAR rheometer are shown in Figure 8 for four selected concrete mixtures. The plots are characterized by an initial linear, elastic response followed by a nonlinear, viscoelastic response up to the peak torque (see Ref. [13, 14] for more discussion of stress growth tests). After the peak torque is reached, viscous flow occurs and the torque begins to decay gradually. The variation in torque readings is typical for stress growth tests of concrete due to the wide range of aggregate sizes present.

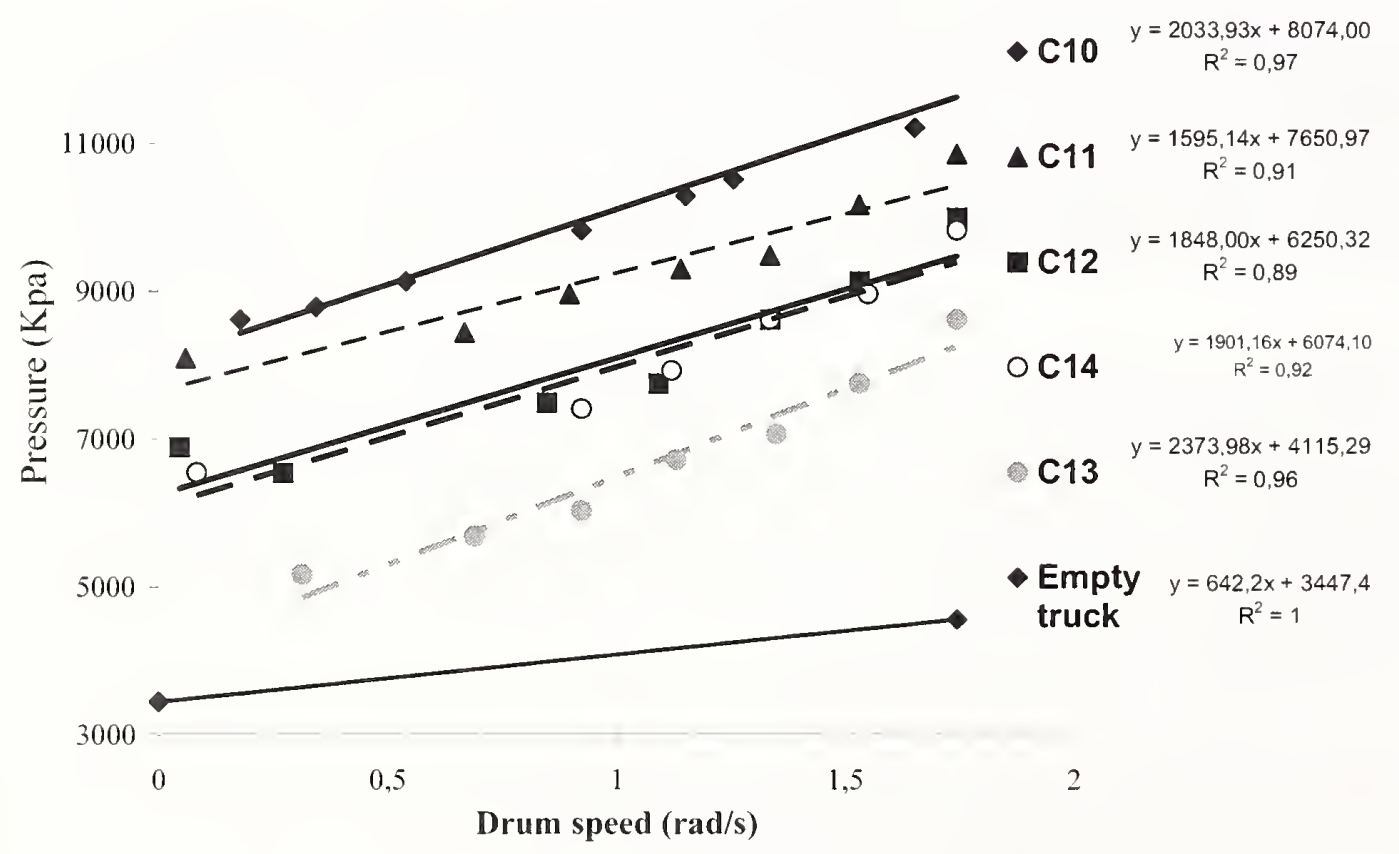

Figure 4: Flow curves obtained with the truck mixer (empty truck, C10 to C14 mixture) 


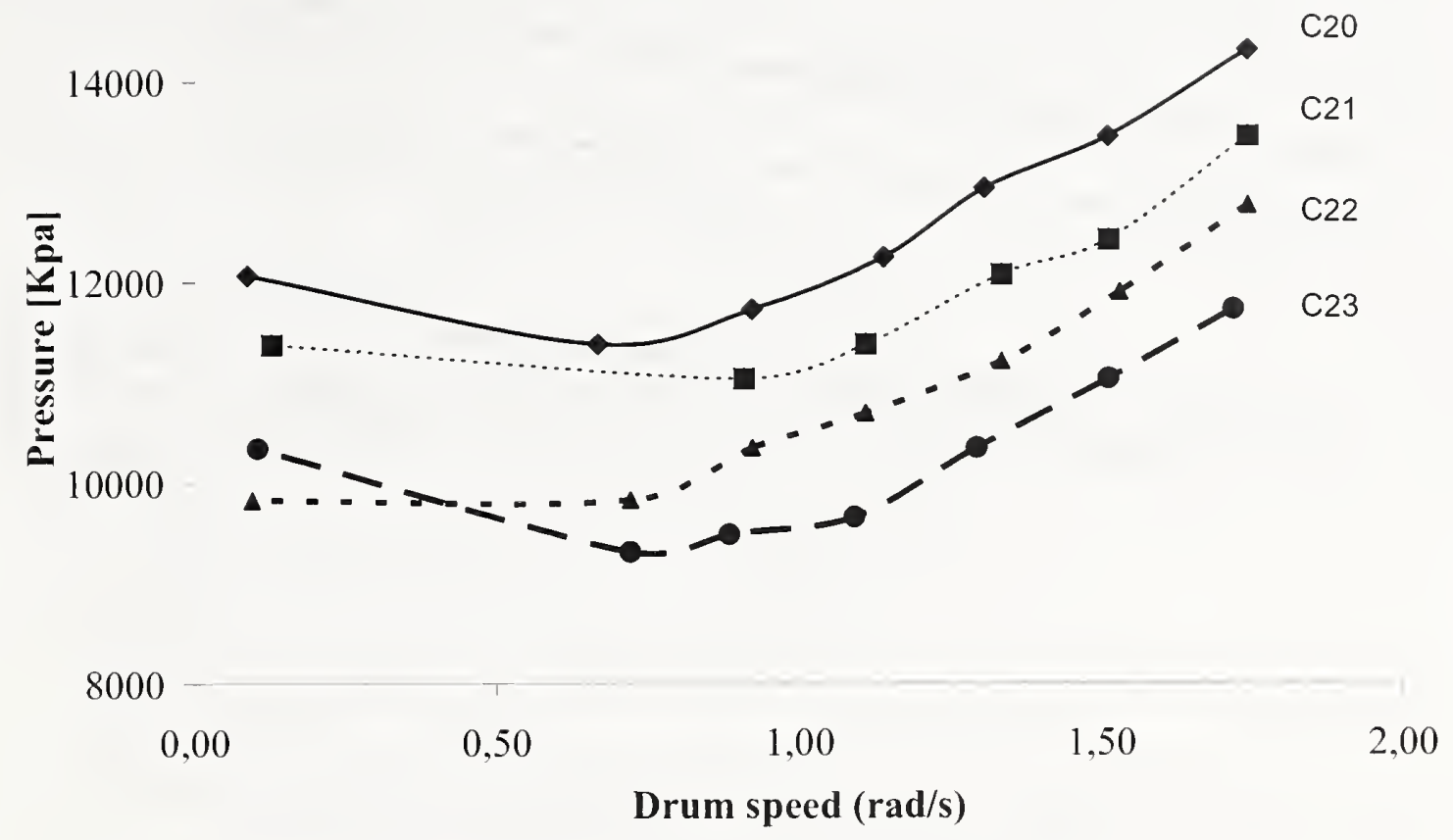

Figure 5: Flow curves obtained with the truck mixer (C20 to C23 mixture)

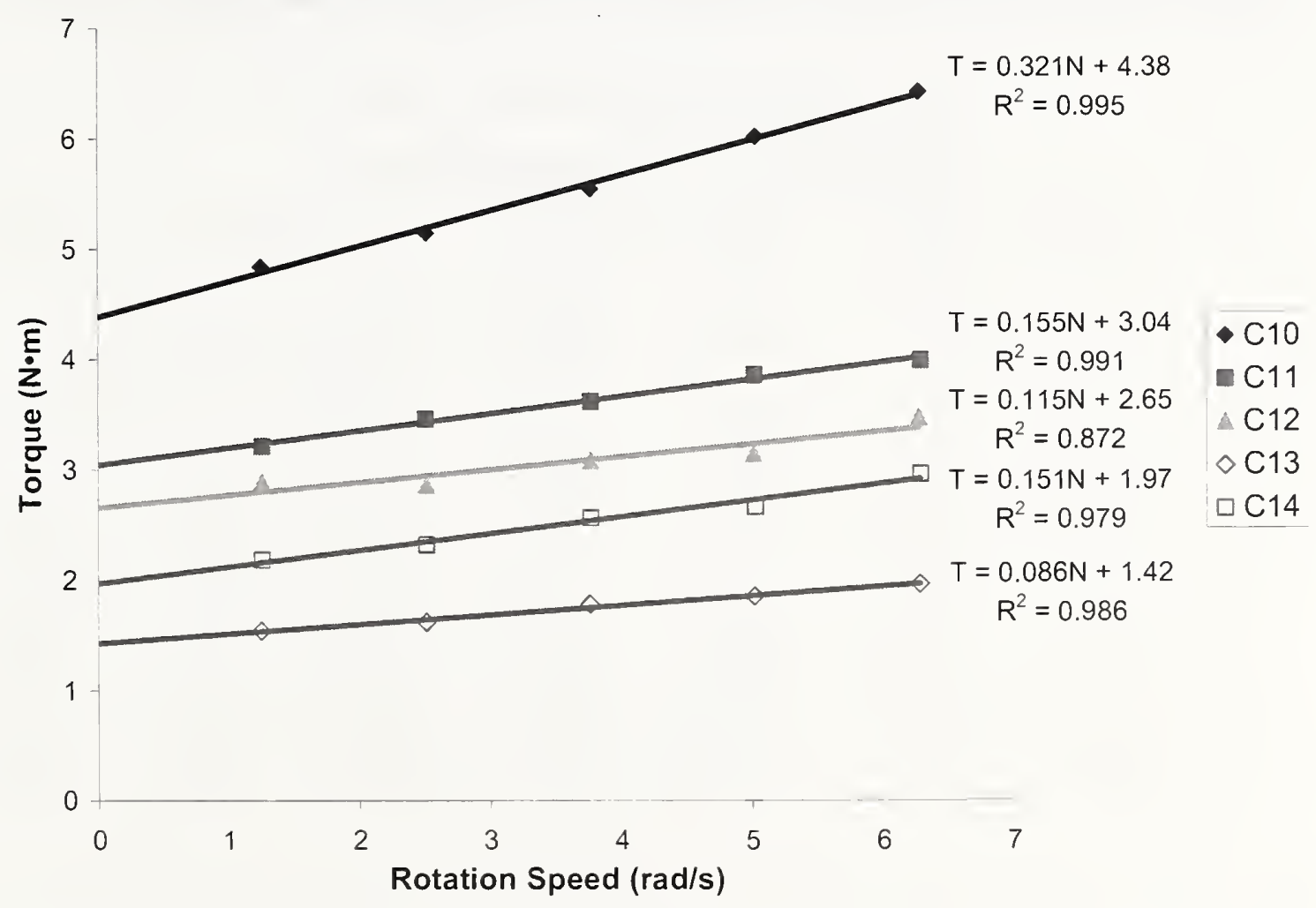

Figure 6 : Flow curves obtained with ICAR rheometer for Series 1 (C10 to C14) 


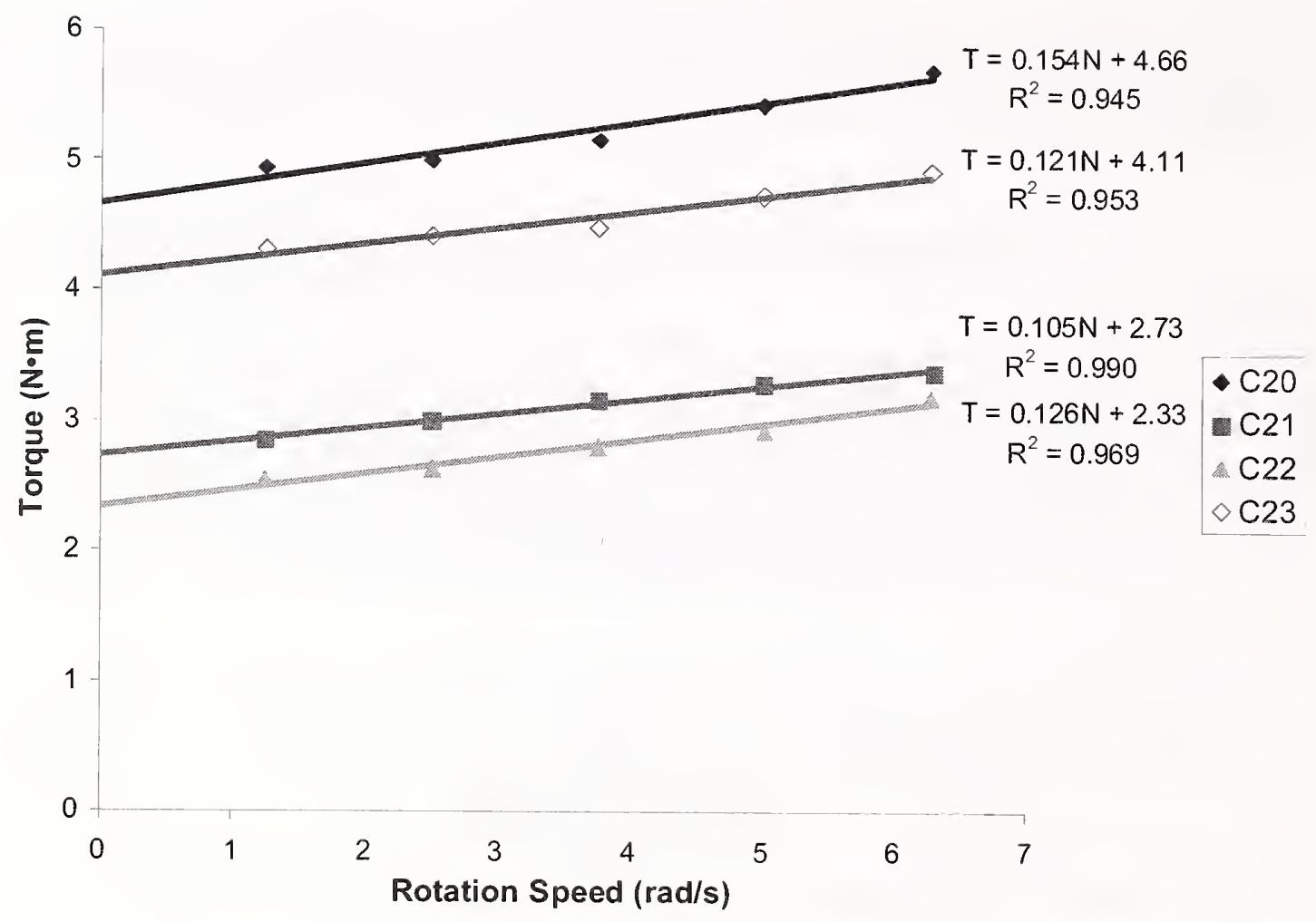

Figure 7 : Flow curves obtained with ICAR rheometer for Series 2 (C20 to C23) 


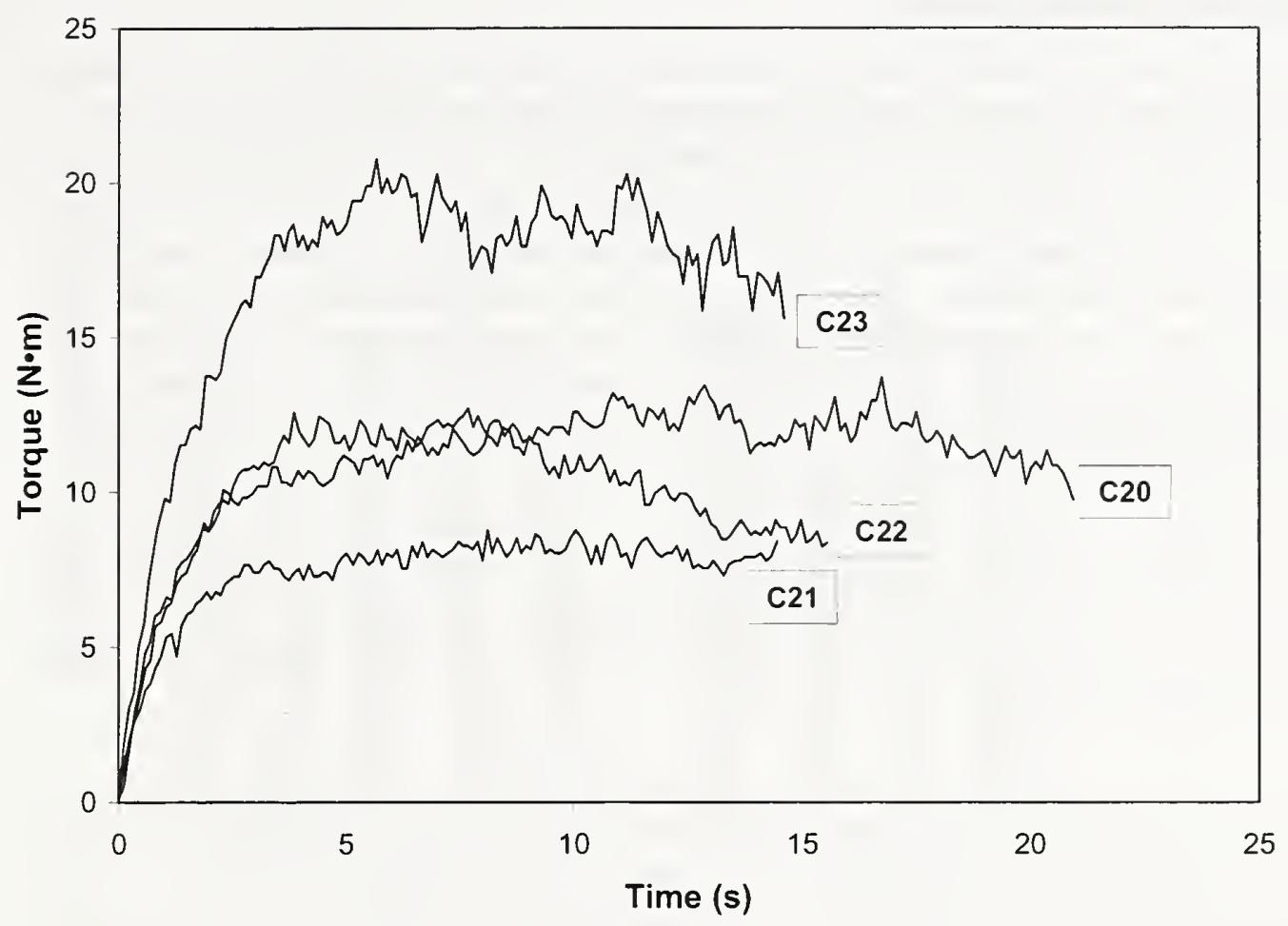

Figure 8: Typical ICAR rheometer stress growth test results for selected mixtures

Table 7: Fresh concrete measurements

\begin{tabular}{|l|l|l|l|l|l|l|}
\hline \multirow{2}{*}{$\begin{array}{l}\text { Mixture } \\
\text { Designation }\end{array}$} & \multirow{3}{*}{\begin{tabular}{l} 
Slump \\
\cline { 3 - 7 }
\end{tabular}} & $\begin{array}{l}\text { Truck Measurements } \\
\text { Yield } \\
\text { Value } \\
(\mathrm{mm})\end{array}$ & $\begin{array}{l}\text { Plastic } \\
\text { viscosity } \\
\text { Value } \\
(\mathrm{kPa} \cdot \mathrm{s})\end{array}$ & $\begin{array}{l}\text { YCAR Rheometer } \\
\text { Value } \\
(\mathrm{N} \cdot \mathrm{m})\end{array}$ & $\begin{array}{l}\text { Plastic } \\
\text { viscosity } \\
\text { Value } \\
(\mathrm{N} \cdot \mathrm{m} \cdot \mathrm{s})\end{array}$ & $\begin{array}{l}\text { Stress } \\
\text { Growth Max } \\
\text { Torque } \\
(\mathrm{N} \cdot \mathrm{m})\end{array}$ \\
\hline Empty truck & & 2131 & 1397 & & & \\
\hline C10 & 70 & 8074 & 2034 & 4.38 & 0.321 & 24.26 \\
\hline C11 & 114 & 7651 & 1595 & 3.04 & 0.155 & 9.98 \\
\hline C12 & 171 & 6250.1 & 1905 & 2.65 & 0.115 & 9.26 \\
\hline C13 & 243 & 4115.3 & 2374 & 1.43 & 0.086 & 4.18 \\
\hline C14 & 152 & 6074 & 1901 & 1.97 & 0.151 & 9.42 \\
\hline C20 & 64 & 8471.9 & 3334 & 4.66 & 0.154 & 13.69 \\
\hline C21 & 121 & 6939 & 3282 & 2.73 & 0.105 & 8.77 \\
\hline C22 & 64 & 6079.7 & 3278 & 2.34 & 0.126 & 12.30 \\
\hline C23 & 38 & 7792.4 & 3177 & 4.11 & 0.121 & 20.77 \\
\hline
\end{tabular}




\subsection{Evolution of Plastic viscosity}

In Figure 9, the plastic viscosity ratio is shown for all the tests performed. The plastic viscosity ratio is defined as the ratio of the measured plastic viscosity for a given test to the plastic viscosity measured for the control mixture C10 or C20. It is necessary to use the plastic viscosity ratio instead of the plastic viscosity value to compare the data from the truck and the rheometer because neither device can produce the plastic viscosity in fundamental units. The viscosity ratio is the only method to compare the two devices [59]. The addition of the first dosage of HRWRA to the control mixture C10 resulted in a decrease in plastic viscosity as measured by both the truck and the ICAR rheometer. Further additions of HRWRA to the same mix, however, produced different results from the two devices. The ICAR rheometer indicated that further additions of HRWRA resulted in further reductions in plastic viscosity while truck measurements indicated that the plastic viscosity began to increase. The use of a viscosity modifying admixture (VMA), a product intended to increase plastic viscosity, for mixture $\mathrm{C} 14$ resulted in an increase in plastic viscosity as recorded by the ICAR rheometer but a decrease in plastic viscosity as recorded by the truck.

In the second series of mixtures, the addition of the first dosage of HRWRA resulted in a decrease in plastic viscosity as recorded by both the truck and ICAR rheometer. Like the first series, the magnitude of the decrease in plastic viscosity was greater for the ICAR rheometer than for the truck measurement. For the final two mixtures, the setting of the concrete began to dominate the rheology. The addition of a second dosage of HRWRA for mixture $\mathrm{C} 22$ resulted in an. increase in plastic viscosity as measured by the ICAR rheometer, while the truck rheometer recorded a value of plastic viscosity that was essentially the same as mixture C21. Finally, the addition of water for mixture C23 resulted in a decrease in plastic viscosity as recorded by both the truck and the ICAR rheometer.

In addition to the flow curve measurements indicated above, a second flow curve was measured with the ICAR rheometer over a lower range of rotation speeds (from 3.1 $\mathrm{rad} / \mathrm{sec}$ to $0.31 \mathrm{rad} / \mathrm{sec}$ ). The concrete sample was remixed by hand between each flow curve measurement; therefore, the second flow curve was measured approximately 3 to 4 min after the first flow curve. In the first measurements $(\mathrm{C} 10)$, the second flow curve points simply extended the original flow curve closer to the origin. However, as the day progressed and the concrete began to set, torque readings at low rotation speeds suggested a negative slope of the curve at low shear rates, as illustrated in Figure 10. As the plastic viscosity is defined as the slope, it would imply that this procedure resulted in the calculation of a negative plastic viscosity, which is not physically possible. The final mixture exhibited not only a negative slope, but an upward shift of the entire curve. This same negative slope was evident in the truck measurements shown in Figure 4. When the rotation speed is sufficiently slow, the microstructure of the concrete is able to reformthat is, the cement particles are able to agglomerate during the shearing process resulting in an increase in torque. This phenomenon of a negative slope of the shear stress-shear rate curve was also observed for cement paste rheological tests where the value of the plastic viscosity was strongly dependent to the shear rate applied and the degree of hydration of the cement paste. Further explanations are presented in [32]. 


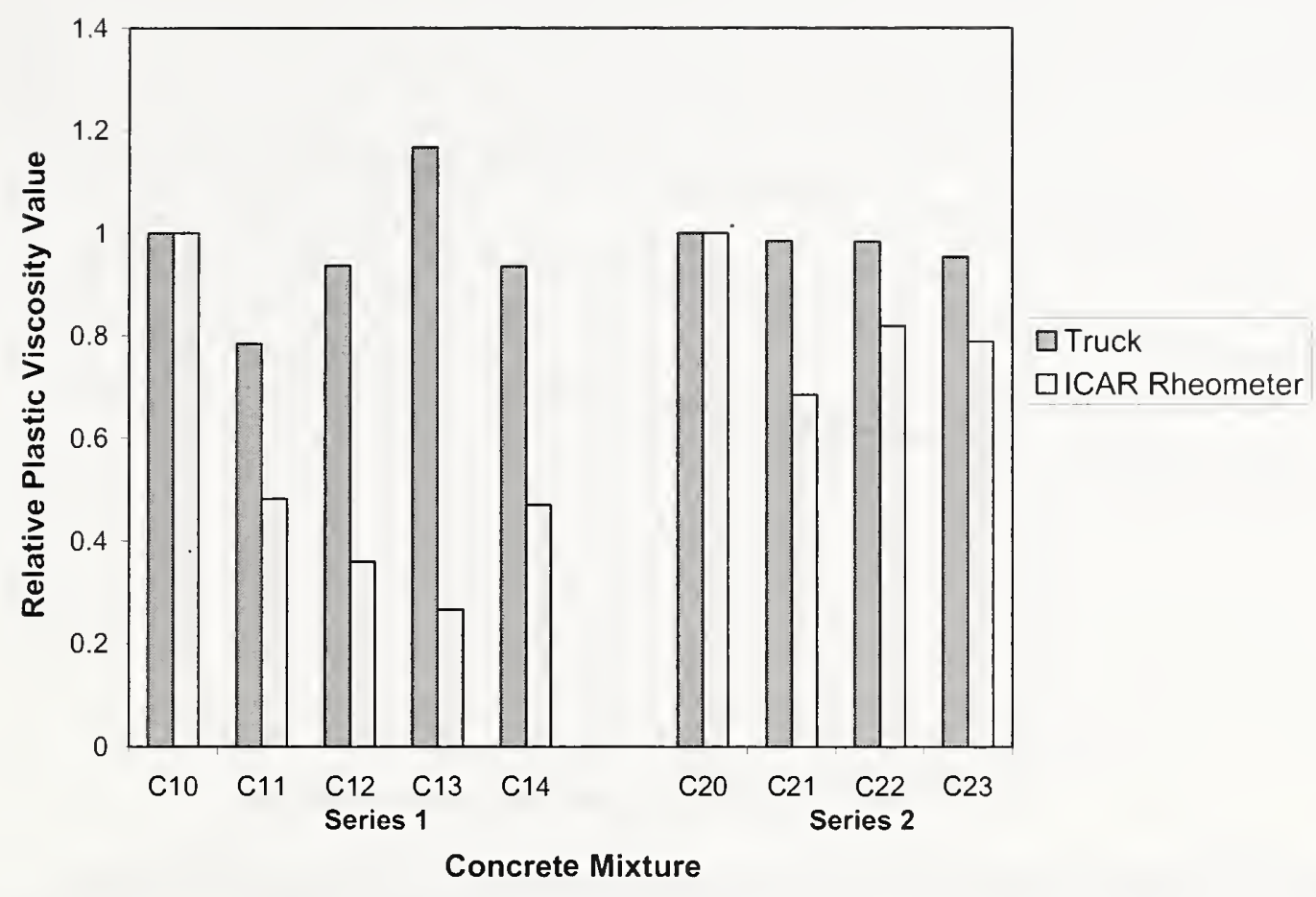

Figure 9 : Relative plastic viscosity, as defined by the ratio of the measured plastic viscosity with the control mixture plastic viscosity, recorded by the mixing truck and ICAR rheometer. The control mixtures are $\mathrm{C} 10$ and $\mathrm{C20}$. 


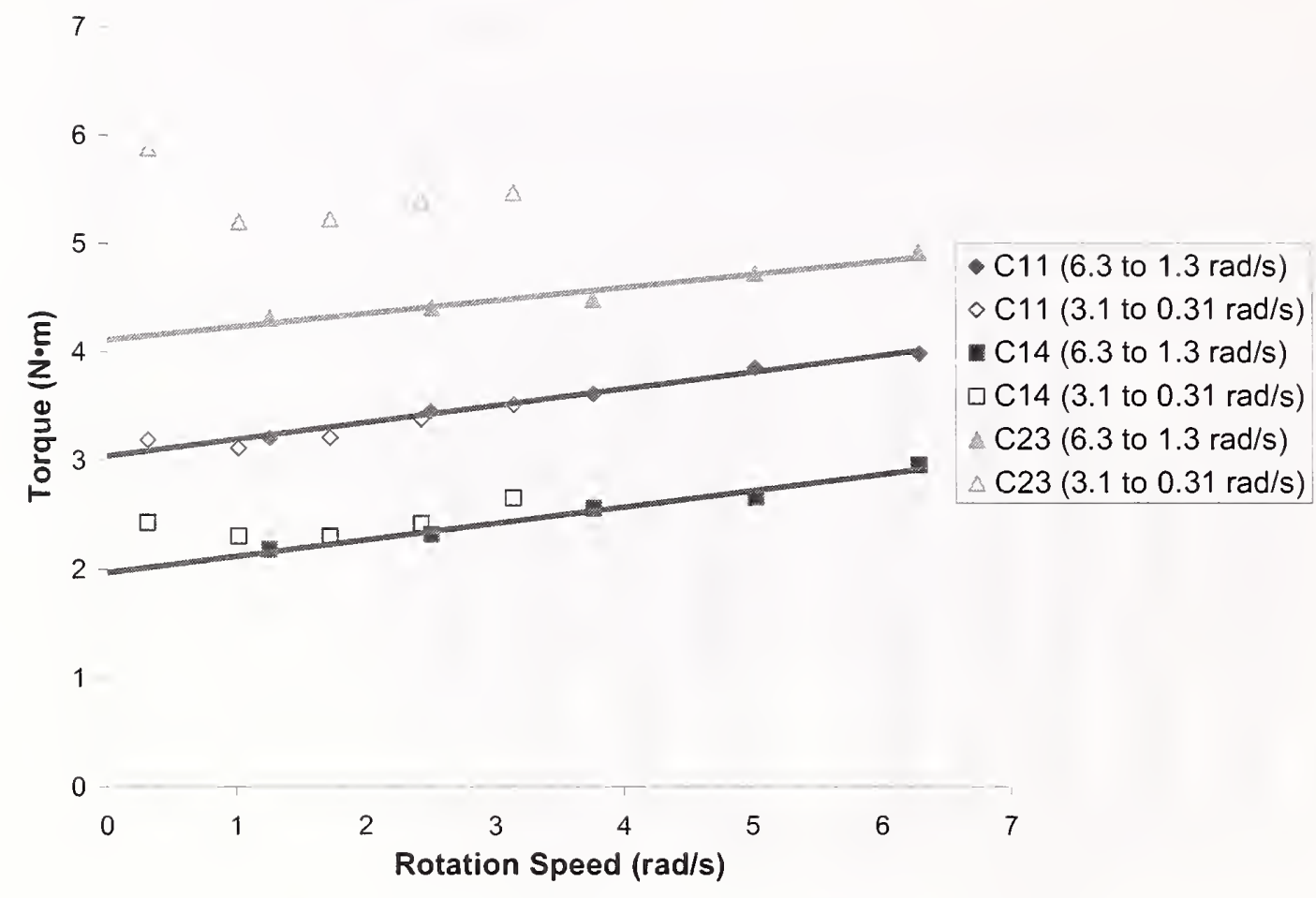

Figure 10: Illustration of slope of the flow curves for selected ICAR rheometer measurements

The correlations between the ICAR rheometer and truck measurements for the plastic viscosity values are shown in Figure 11. No apparent relationship exists for plastic viscosity. This disappointing result could be attributed to the lack of precision of the pressure gauge $( \pm 0.34 \mathrm{MPa}$ or $50 \mathrm{psi}$ accuracy), especially at pressures less than 3.45 $\mathrm{MPa}(500 \mathrm{psi})$ where the lack of graduation below this lower value prevented measurements. Nevertheless, the results show that the truck is able to sense differences between the mixes as the plastic viscosity varies between $1500 \mathrm{kPa} \cdot \mathrm{s}$ and $4000 \mathrm{kPa} \cdot \mathrm{s}$. 


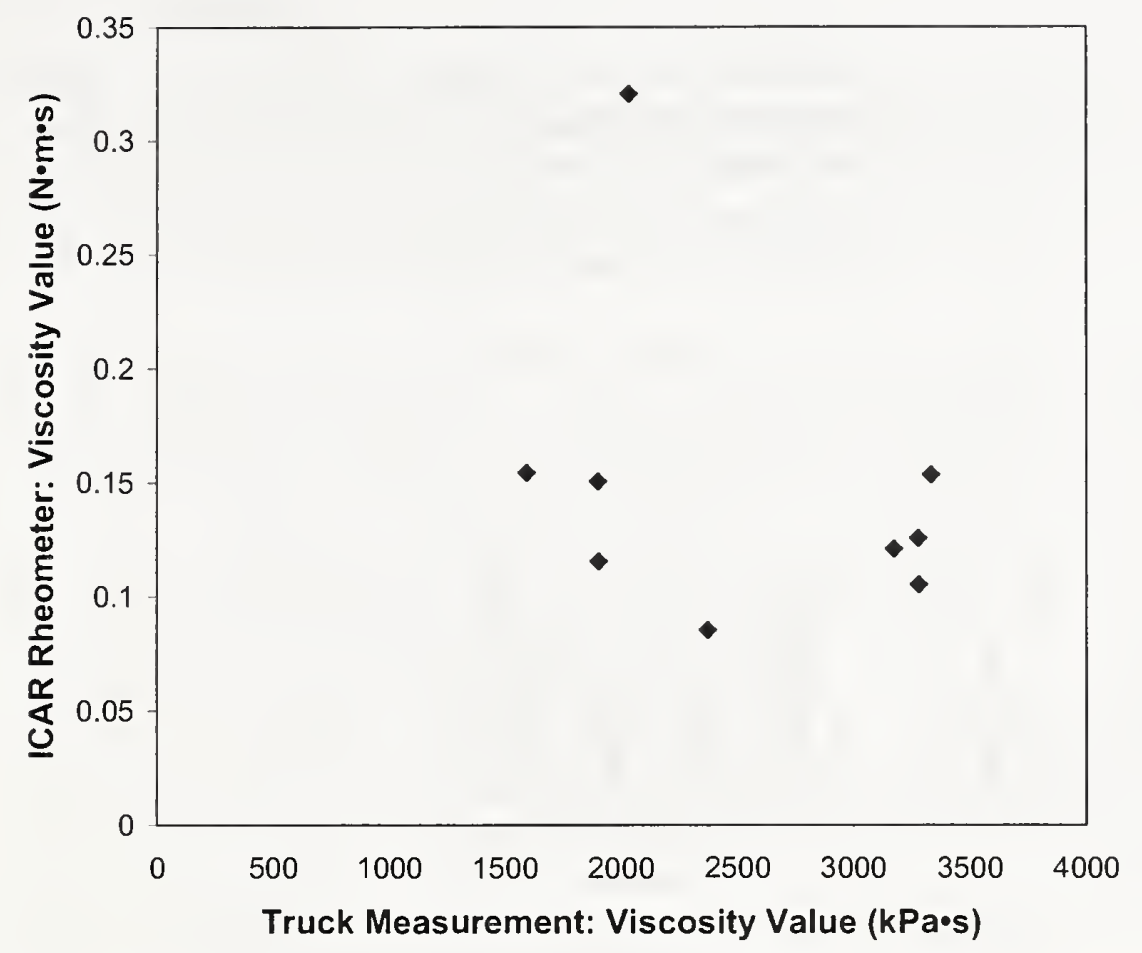

Figure 11: Correlation of plastic viscosity value between ICAR rheometer and truck

\subsection{Evolution of yield stress}

The relative variations in yield stress as recorded from the truck measurements, ICAR rheometer, and the slump test are shown in Figure 12. The results between different tests are generally consistent. The addition of HRWRA for mixture $\mathrm{C} 11, \mathrm{C} 12$, and $\mathrm{C} 13$ resulted in decreases in the yield values measured by both the ICAR rheometer and the truck. Many authors $[60,61,62]$ have shown that concrete slump is negatively correlated to yield stress. Indeed, the slump increased as the truck measurements and ICAR rheometer indicated a reduction in yield stress due to the addition of HRWRA. The use of plastic viscosity-modifying admixture for mixture $\mathrm{C} 14$ resulted in increases in yield value as determined by both the truck and the ICAR rheometer and a decrease in slump as compared to mixture C13. For the second mixture, the use of HRWRA again resulted in reductions in yield value as determined by the ICAR rheometer and the truck and an increase in slump. As with the plastic viscosity values. the yield values were dominated by the setting of the concrete for the last two mixtures. As shown in Figure 13, the yield stress measurements from the ICAR rheometer and the truck were well correlated. 


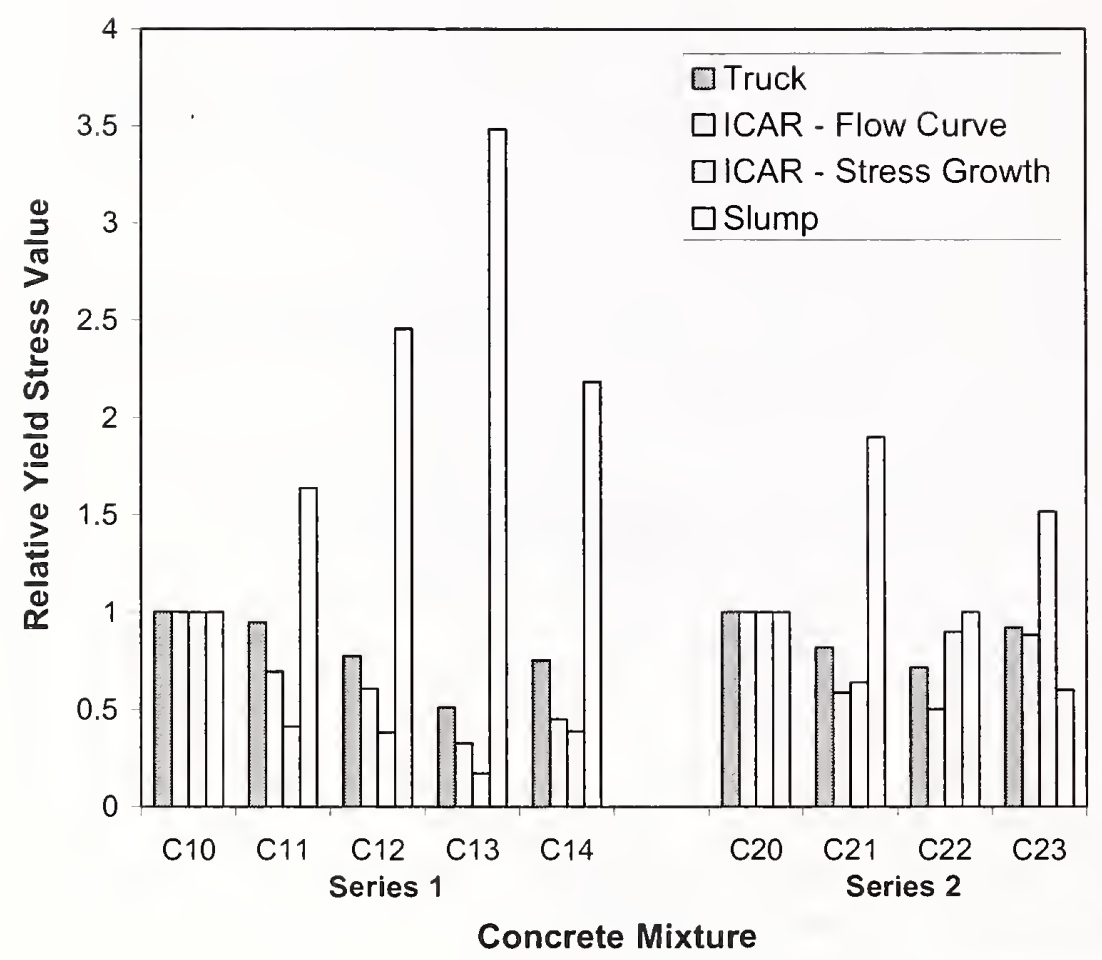

Figure 12: Relative yield values, as defined by the ratio of the measured yield stress with the control mixture yield stress, as recorded by mixing truck, ICAR rheometer, and slump test. The control mixtures are $\mathrm{C} 10$ and $\mathrm{C20}$.

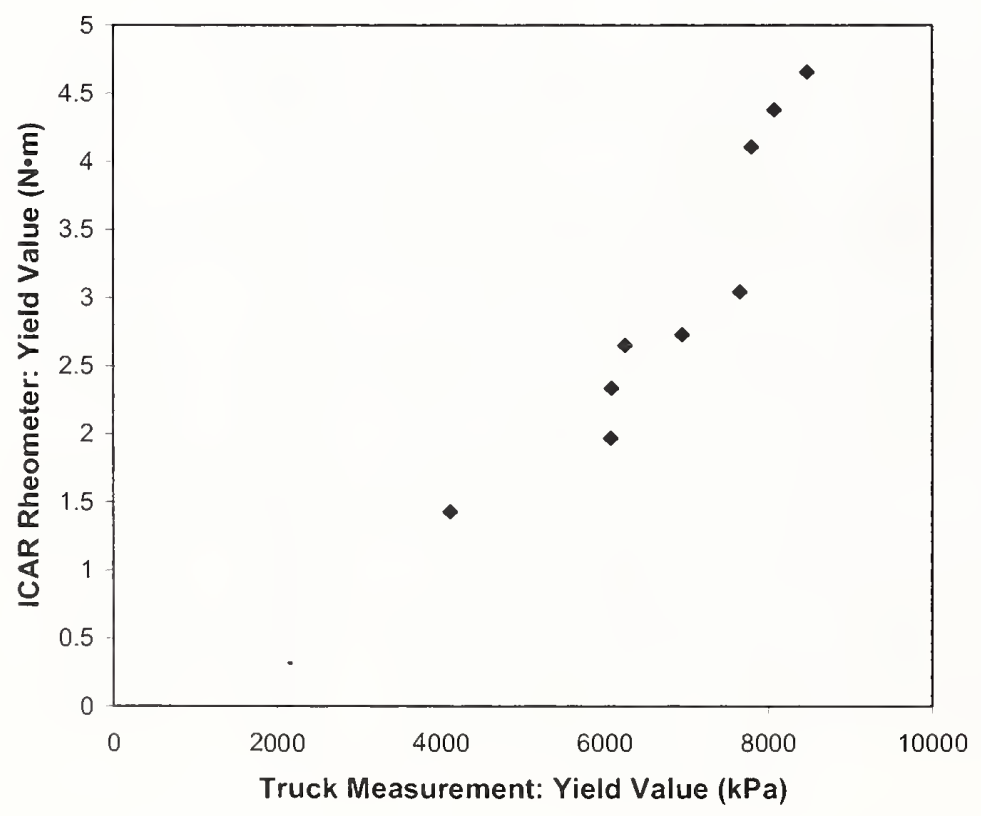

Figure 13: Correlation of yield value between ICAR rheometer and truck 


\subsection{Conclusions}

Based on the limited investigation (only one day of testing) of the feasibility of measuring rheological properties directly in a mixing truck without any modifications, it was determined that the mixing truck is itself a tool to obtain flow curves of the mixed material as in any rheometer and that the flow curves measured by the mixing truck were sensitive to changes in yield stress and plastic viscosity.

The comparison of the yield stress measured with the slump test, the ICAR rheometer and the mixing truck showed a relative good correlation between the values measured. On the other hand, the plastic viscosity measured by the truck or the ICAR rheometer did not show a high correlation. The results of the ICAR rheometer measurements appeared to be more realistic than the truck measurements as far as changes in plastic viscosity due to addition of admixtures or water were concerned. This situation could be attributed to various factors. For instance, the truck measurements had several sources of errors in the precision of the measurements of the drum rotation speed and torque. A more precise gauge for the torque is more essential, as it is probably the larger error source. An automated speed measurement would also be desirable, although it is probably not a major source of error in this study. Calibration methods are needed to obtain the results in fundamental units and to better compare the test results with other rheometers. A more accurate knowledge of the drum geometry might also lead to the calculation of the rheological parameters in fundamental units.

In summary, this preliminary study showed the feasibility of measuring the slope and intercept of the torque vs. speed plot from a mixing truck drum as a means of determining concrete workability. The yield stress measured with this method correlated well with the results of the slump test and the ICAR rheometer. More extensive studies are needed for a reliable measurement of the plastic viscosity. 


\section{General Conclusions}

The goal of this study was to determine the feasibility of using a concrete mixing truck as a rheometer. The approach was to first examine the literature and then to carry out a field experiment.

The state of the art portion of this report concentrated on three topics:

- Energy needed for mixing

- Relationship between mixing and rheology

- Mixing in a concrete truck

Some historical background was given on concrete mixing trucks as well.

The main conclusion of this preliminary study is that it is possible to determine the yield stress and the plastic viscosity of a mixture if the following concrete mixing truck parameters can be determined with precision:

- Mass of the materials placed in the truck: this will allow the calculation of the relative energy of mixing per mass of material

- Geometry of the mixing blade and the speed of rotation of the truck drum and especially the diameter of the drum and the precise geometry of the blade (step, angle of the spiral and the length of the blade). These geometrical factors will allow the determination of the shear rate $\dot{\gamma}$ of the concrete.

- Measurement of the speed of rotation of the drum. Once the mixture is properly mixed at least 5 speeds should be controlled $(5 \mathrm{rpm}, 10 \mathrm{rpm}, 15 \mathrm{rpm}, 20 \mathrm{rpm}, 25$ rpm).

- The torque induced by the concrete to the drum, which is determined by the size of the engine that turns the drum. The torque is also related with the hydraulic pressure (easily measured). The torque measurement should be sensitive enough to enable measurements even when the truck is empty of concrete. This will give a base line.

The measurement of the torque and speed allow the determination of the plastic viscosity of the concrete as a function of the shear rate and the volumetric power.

Obviously, more tests are necessary to determine the error of the measurements. Calibration of the measurements to determine the plastic viscosity and yield stress in fundamental units still needs to be developed. 


\section{References}

$1 \quad$ Koehler E.P., Fowler D.W., "Summary of Concrete Workability. Test Methods", ICAR Report 105.1, International Center for Aggregates Research, Austin, TX, (2003).

2 Ferraris C.F., Brower L. editors, "Comparison of concrete rheometers: International tests at LCPC (Nantes, France) in October 2000", NISTIR 6819 (2001).

3 Ferraris C.F., Brower L. editors, "Comparison of concrete rheometers: International tests at MB (Cleveland OH, USA) in May 2003", NISTIR 7154 (2004).

4 Amziane S., Ferraris C.F., Koehler E.P., "Measurement of Rheological Properties of Fresh Concrete Using a Mixing Truck", J. Res. Natl. Inst. Stand. Technol. Vol. 110, pp. 55-66 (2005).

$5 \quad$ Koehler E.P., "Development of a Portable Rheometer for Portland Cement Concrete," MS Thesis, The University of Texas at Austin, Austin, TX. (2004).

6 Gaynor R.D., "Ready Mixed Concrete," Significance of Tests and Properties of Concrete and Concrete-Making Materials, ASTM STP 169C, ASTM, West Conshohocken, PA, pp. 511-521, (1994)

7 ASTM C 94 "Standard Specification for Ready-mixed Concrete," ASTM, 1916 Race St., Philadelphia, PA 19103.

8 "Truck Mixer and Agitator Standards," Truck Mixer Manufacturers Bureau, affiliated with National Ready Mixed Concrete Association, 900 Spring St., Silver Spring, MD 20910.

9 Suprenant B.A., "Mixing concrete in the truck takes proper procedures". Publication \#J921112, The Concrete Producer/Concrete Journal, January, (1992)

10 Brower L.E., Ferraris C.F., "Comparison of Concrete Rheometers", Concrete International, 25 (8), 41-47 (2003).

11 Daczko J.A., "A proposal for measuring rheology of production concrete", Concrete International, 22 (5), 47-49 (2000).

12 de Larrard F., Cazacliu B., Chopin D.. Chateau E., "Production of SCC", Proceedings of the 3rd International RILEM Symposium, Reykjavik, Iceland, 1720 August 2003, Edited by O. Wallevik and I. Nielsson, (RILEM Publications), 1 Vol., 1048 pp., ISBN: 2-912143-42-X, (2003). 
13 Chopin D., "Malaxage des bétons à hautes performances et des bétons autoplaçants : Optimisation du temps de fabrication" Collection Études et recherches des LPC - série Ouvrages d'art - n 41, Issn 1161-028X (2003).

14 Ferraris C.F., de Larrard F., "Modified Slump Test to Measure Rheological Parameters of Fresh Concrete" Cement, Concrete and Aggregates, Vol. 20 \#2, pp. 241-247 (1998).

15 Beitzel H., "Efficiency of concrete mixers - Report on assesment and classification of performance of mixers", Rilem TC-150-ECM (1998).

16 Charonnat Y., Beitzel H., "RILEM TC 150 ECM: Efficiency of concrete mixers; report: efficiency of concrete mixers towards qualification of mixers", Mater. Struct. (Suppl. 196) 30, 28-32 (1997).

17 Charonnat Y., "Les betonnieres portees. Caracteristiques et mode d'utilisation", Bull. De liaison du Laboratoire des Ponts et Chaussees" Special XII, Materiels de Travaux Public, pp 71-84 (1982).

18 Boussion R., Charonnat Y., "Les bétonnières portées sont-elles des melangeurs ?", Bull. De liaison du Laboratoire des Ponts et Chaussees, n 149, ref 3160, pp75-87 (1987).

19 Ferraris, C.F., "Concrete Mixing Methods and Concrete Mixers: State of the Art", Journal of Research of the National Institute of Standards and Technology, Vol. 106, No. 2, 391-399 (2001).

20 Beitzel H., "Concrete production plants and mixers some aspects of their design and operation, Part 2", Beton + Fertigteil-Technik 5, 305-310 (1984).

21 Kaarst R. S., "Concrete Mixers and Mix Systems", Concrete Precasting and Technology, V64, 0373-4331 BWFTAB, pp. 88-98 (1998).

22 Takada K., Pelova G., Walraven J.C., "Influence of mixing efficiency on the fresh properties of self-compacting concrete", Technical session : manufacturing and concrete products, International Workshop on self-compacting Concrete, pp 368383 (1998).

23 Yang M., Jennings H.M., "Influences of mixing methods on the microstructures and rheological behavior of cement paste", Advanced Cement Based Material, 2, pp 70-78 (1995).

24 Steiger R.W., "The history of concrete", Concrete Producer, (1995).

25 Steiger R.W., "Concrete mixing in the late $19^{\text {th }}$ century", Concrete Producer (1994). 
26 Steiger R.W., "Concrete mixing in the late $20^{\text {th }}$ century", Concrete Producer (1995).

27 Orban J.A., Shlumberger A., Parcevaux P.A., Guillot D.J., "Specific Mixing Energy : A key factor for cement slurry qulity". SPE 15578, Society of Petrolium Engineers, $61^{\text {st }}$ Annual Technical Conference and Exhibition of the SPE (1986).

28 Hibbert A.P., Kellingray D J., Vidick B., "Effect of mixing energy levels during batch mixing of cement slurries". SPE Drilling \& Completion, pp. 49-52, (1995).

29 Tatersall G. H., Banfill P. F. G., "The rheology of fresh concrete", Pitman Advanced Publishing Program (1983).

30 Scullion T., "The measurement of the workability of fresh concete", MA Thesis, University of Sheffield (1975).

31 Padgett $P$., "Shear rate has greater influence on cement slurry properties than total mixing energy", The Oil and Gas Journal, V 94, N 41, pp 84-91 (1996).

32 Amziane S., Ferraris C.F., "Setting Evolution using Rheological and Hydraulic Pressure Measurements", submitted to ACI Material Journal (2006).

33 Helmuth R., Hills L., Whitting D., Bhattacharja S., "Abnormal Concrete Performance in the Presence of Admixtures" Portland Cement Asoociation \#2006 (1995).

34 Chopin D., de Larrard F., Cazacliu B., "Why do HPC and SCC require a longer mixing time?", Cement and Concrete Research, Volume 34, Issue 12, Pages 2237-2243 (2004).

35 Roy D.M., Asaga K., "Rheological properties of cement mixes: III. The effects of mixing procedures on viscometric properties of mixes containing superplasticizers", Cement and Concrete Research. Vol. 9, pp. 731-739 (1979).

36 Hodne H., Saasen A., O'Hagan A. B., Wick S. O., "Effects of time and shear energy on the rheological behaviour of oilwell cement slurries", Cement and Concrete Research, V.30, pp 1759-1766 (2000)

37 Campbell P., "Who Invented the Portable Mixer Anyway?", Concrete Producer. (2000).

38 Gaynor R.D., Mullarky J.I., "Mixing concrete in a truck mixer", NRMCA. National Ready Mixed Concrete Assossiation, publication n.148, pp. 1-25 (1975). 
40 http://www.liebherr.com/mt/en/23417.asp

41 http://www.cement.org/

42 Gottfried K., "New Trends in European Ready-Mixed Concrete Production", Concrete Producer, (February 1999)

43 http://www.nrmca.org/concrete_basics/delivery_rmc.html

44 Ahmad I., Salman Azharand S., Sobanjo J., "Lumps and Balls in High-slump Concrete: reasons and remedy", Florida Department of Transportation (FDOT), Final Report, $B C 837$ (2002).

45 United States Patent, 6,227,039,B1, "System and method for controlling concrete production",(2001).

46 United States Patent, 4,900,154, "Concrete mixer having means for determining the consistency of concrete mixing therein", (1990).

47 United States Patent 3,924,447, "Slump indicator", (1975).

48 United States Patent 3,403,546. Stratton, "Slump indicator for concrete", United States Patent,.(1968).

49 United States Patent 3, 237, 437 L.G. Hilkeimeier, "Slump Meter", (1966).

50 United States Patent, 2,821,079, "Apparatus for measuring concistency during mixing of concrete", (1958).

51 United States Patent, 2,643,542, "Apparatus for determining the consistency of concrete mix", (1953).

52 United States Patent, 2,629,790, "Apparatus for measuring and/or controlling the consistency of a paste or slurry", (1953).

53 United States Patent 2,409,014, "Mix-consistency indicator for concrete mixers", (1944).

54 United States Patent 1,898,890 and 2,013,837, "Concrete mixometer and Consistency and time indicating and recording equipment for concrete", (1933 and 1935).

55 United States Patent 1,730,893 (1929), "Method of and apparatus for determining the consistency of concrete",.

56 Beaupré D., "Rheology of High-Performance Shotcrete", PhD Thesis, University Of British Columbia (1994) 
57 Barnes H.A., and Nguyen Q.D., "Rotating vane rheometry-a review." Journal of Non-Newtonian Fluid Mechanics, V. 98, No. 1, pp. 1-14 (2001).

58 Saak A.W., Jennings H.M., Shah S.P., "The influence of wall slip on yield stress and viscoelastic measurements of cement paste" Cement and Concrete Research, 31(2), 205-212, (2001)

59 Ferraris C.F., Martys N.S., "Relating Fresh Concrete Viscosity Measurements from Different Rheometers", J. Res. Natl. Inst. Stand. Technol., 108 (2003).

60 Flatt R.J., "Towards a prediction of superplasticized concrete rheology", Materials and Structures / Materiaux et Constructions, Vol 37, 289-300, (2004).

61 Ferraris C.F., de Larrard F., "Testing and Modeling of Fresh Concrete Rheology", NISTIR 6094, National Institute of Standards and Technology, Gaithersburg, MD (1998).

62 Schowalter W. R., Christensen G., "Toward a rationalization of the slump test of the fresh concrete: Comparison of Calculations and Experiments", J. Rheol., 42 (4) $865-870$ (1998). 




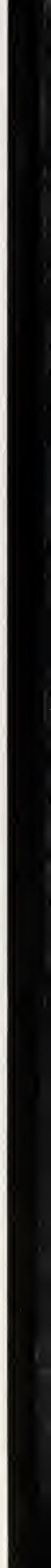

